\title{
Semicentralized Power Sharing Scheme for Islanded Parallel-Connected Inverters
}

\author{
Mohd Azrik Roslan $\left(\mathbb{D},{ }^{1}\right.$ Khaled Ahmed $\mathbb{D}^{1},{ }^{1}$ Grain Adam $\mathbb{D}^{1},{ }^{1}$ Ahmad Elkhateb $\mathbb{D}$, ${ }^{2}$ \\ Walid Issa $\mathbb{D}^{3},{ }^{3}$ and Barry Williams ${ }^{1}$ \\ ${ }^{1}$ Department of Electronic and Electrical Engineering, Strathclyde University, Glasgow G1 1XQ, UK \\ ${ }^{2} S$ chool of Electronics Engineering and Computer Science, Queen's University, Belfast BT9 5AH, UK \\ ${ }^{3}$ Department of Electrical and Electronic Engineering, Sheffield Hallam University, Sheffield S1 1WB, UK
}

Correspondence should be addressed to Walid Issa; walid.issa@shu.ac.uk

Received 6 November 2021; Revised 14 December 2021; Accepted 26 January 2022; Published 7 March 2022

Academic Editor: Akshay Kumar Saha

Copyright (c) 2022 Mohd Azrik Roslan et al. This is an open access article distributed under the Creative Commons Attribution License, which permits unrestricted use, distribution, and reproduction in any medium, provided the original work is properly cited.

\begin{abstract}
This paper presents a new control scheme that permits flexible power sharing between parallel inverters connected to microgrid operating in an island mode. The presented scheme processes the information of active and reactive output powers from all inverters in a central controller that calculates the set points for each inverter, based on the desired ratios of their output powers. These necessitate adjustment of the inverters' terminal voltages (phase and magnitude) relative to the voltage at the common AC bus. The proposed power-sharing scheme uses a robust low bandwidth-based sharing communication to achieve precision and fast dynamic response, minimum circulating current between parallel inverters, and adapting to changes in line impedance, even under information transfer delays. The presented power-sharing scheme has been validated using MATLAB/Simulink simulation and experimental results obtained from a prototype of three three-phase parallel inverters connected to a number of loads. The results emphasize the superiority of the proposed topology performance under different loads (25\% to $100 \%)$, line impedances, grid conditions, and communication delay.
\end{abstract}

\section{Introduction}

Increasing demand for large-scale power delivery with high reliability necessitates the use of multiple distributed energy resources (DERs) to be connected in parallel; for example, parallel inverters in microgrid operation [1]. The proper operation of the parallel inverters requires sophisticated control techniques. Many of these techniques have been proposed in the past decades and continue to evolve [2].

Among several methods for controlling parallel inverters, a frequency-voltage droop method is well established and commonly used, with proven track record [3]. This technique mimics the operation of a large-scale power system that uses predefined droop characteristic that relates generator speed and output active power. This technique is also known as wireless control as no communication required between the inverters, thus making it simple to implement and reliable [4]. However, it has several disadvantages that can degrade its performance. Some of its shortcomings are as follows: its frequency and amplitude deviations are load dependent, hence resulting in poor load voltage regulation performance; inherent tradeoff between the voltage regulation and the power sharing between the inverters; and impedance mismatched among inverters affects the power sharing performance [5].

In recent years, there are many modifications that have been proposed to improve the performance of the droop control method in order to meet the increasing demands of microgrids. Some of the proposed modifications are the modified droop [6-8], adaptive droop [9-11], combined droop [12-14], and networked droop control schemes [15-18].

In [6], power derivative-integral terms are introduced into a conventional droop scheme to improve its transient 
response. However, it is difficult to select the suitable coefficients for the derivative term that ensures the stable system operation. In [11], the authors proposed a combined static droop characteristics with an adaptive transient droop function to ensure active damping of power oscillations. However, the authors did not present experimental validation for this technique. In [16], the authors proposed an improved droop technique that uses web-based low bandwidth communication to improve the load sharing performance. This technique achieves good active power sharing in a low voltage network, but the authors did not present the results for reactive power sharing. A droop control with an optimization algorithm is introduced in [13]. It uses particle swarm optimization to optimize the droop constant. It shows good active and reactive power sharing in simulation, but there is no hardware verification.

Recently, it has been recognized that excellent current sharing and voltage regulation in a parallel system can be achieved by sharing some information among parallelconnected inverters. Examples of the control techniques that utilize communication among parallel inverters are active load sharing techniques. They can be classified as circularchain current technique [19], master-slave technique [20], and the average current sharing technique [21, 22]. In the circular-chain current technique, successive inverter modules track the current of the previous inverter to achieve an equal current distribution. However, the main weakness of this approach is that it heavily relies on communication bringing robust uncertainty to the system. The master-slave technique utilizes one inverter to regulate the amplitude and frequency, and remaining inverters act as slaves that inject currents. In the average current sharing technique, all the inverters in the microgrid contribute to voltage, frequency, and current regulations. Additionally, the average current information is calculated by averaging the inverter current injection into a common bus and shared as a reference for each module.

The previous discussions have shown that both droop and active load sharing techniques have their own advantages and drawbacks. The methods to address the drawback diverse from communication to communicationless methods. In some applications, the inverters have tight loading requirements to prevent overheating and preserve longer lifetime, and accurate sharing of active and reactive power is crucial. Having the flexibility to modify the power references while keeping accurate sharing and damped responses will facilitate those applications. Therefore, it is desirable to have a control technique that is flexible and reliable with good voltage regulation and current sharing properties, and reduced circulating current, with minimum low-cost communication and robust for communication delays.

This paper proposes a new power-sharing algorithm that requires low bandwidth communication with a central controller. The central controller receives active and reactive power information from all parallel-connected inverters and calculates active and reactive power references for each inverter. These references are calculated based on the specified ratio of output power of each inverter. Based on this information, each inverter adjusts its voltage reference phase and amplitude relative to the common AC bus to achieve the required output power. This technique adjusts the phase (not the frequency); hence, it can achieve good frequency regulation.

The proposed controller can be considered as a strong candidate for module inverter design where the capability can be extended per request. This controller brings scalability and flexibility with accuracy to achieve a wide range of power.

This paper is organized in seven sections. Brief review of power flow theory is presented in Section 2. The system structure and proposed power sharing technique are discussed in Section 3. Section 4 presents the stability analysis of the proposed technique. Sections 5 and 6 present the MATLAB/Simulink simulation and experimental results, respectively, to confirm the validity and effectiveness of the proposed technique. The major findings and contributions of this paper are highlighted in the conclusions in Section 7.

\section{AC Power Flow Analysis}

The equivalent circuit of inverter connected to the common $\mathrm{AC}$ bus is shown in Figure 1. The complex power injected by an inverter to the common AC bus is given as follows [23]:

$$
S=P+j Q
$$

where $P$ is the active power and $Q$ is the reactive power. Figure 1 shows the simplest equivalent circuit for an inverter exporting/importing power from the grid where $E$ is the amplitude of inverter output voltage measured at filter bus, $V$ is the common bus voltage amplitude, and $\alpha$ is the power angle. $Z$ and $\theta$ are the magnitude and phase of the overall system impedance, which consist of resistance and inductive reactance, $R$ and $j \omega L$.

The dominant factors to control the active and reactive powers depend on the line impedance being inductive or resistive which were investigated more in $[5,24]$. It is important to mention here that the low voltage network is dominantly in resistive nature (low $L / R$ ratio). However, it has been realized that the output impedance can be shaped [25] to be dominantly inductive or resistive using the virtual impedance loop within the voltage control loop [26].

Figure 2 shows the active and reactive power plots for different voltage levels and under highly inductive and resistive impedance conditions when the power angle is varied. It is assumed that the voltage amplitude at the inverter filter bus is the same as that at the common AC bus. Active and reactive power plots for different voltage levels and under highly inductive and resistive impedance conditions when the inverter's voltage amplitude is varied are shown in Figure 3. In this case, it is assumed that the power angle $\alpha$ is kept at $0^{\circ}$. For inductive line impedance, $X$ is set to $1.57 \Omega$, and for resistive line impedance, $R$ is set to $0.3 \Omega$.

Figure 2(a) shows that for inductive line impedance, inverter active power output increases as the power angle increases and vice versa. The rate of active power change increases at a higher voltage level, while there is no 


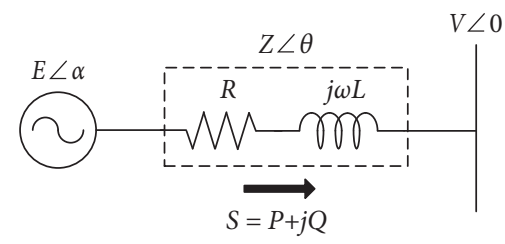

Figure 1: Equivalent circuit of inverter connected to common AC bus [5].

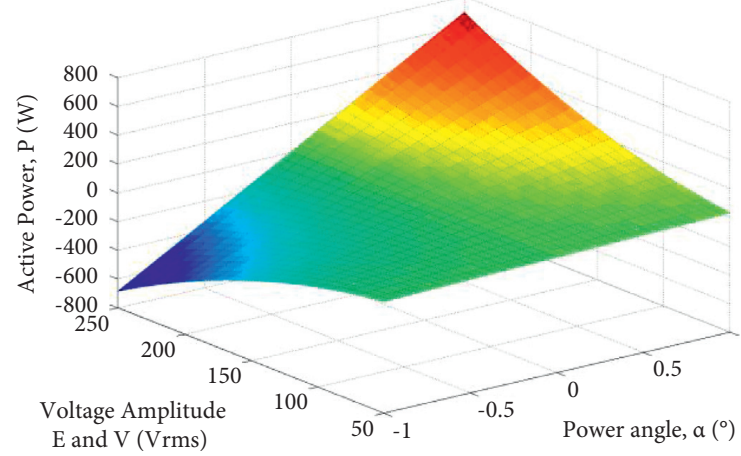

(a)

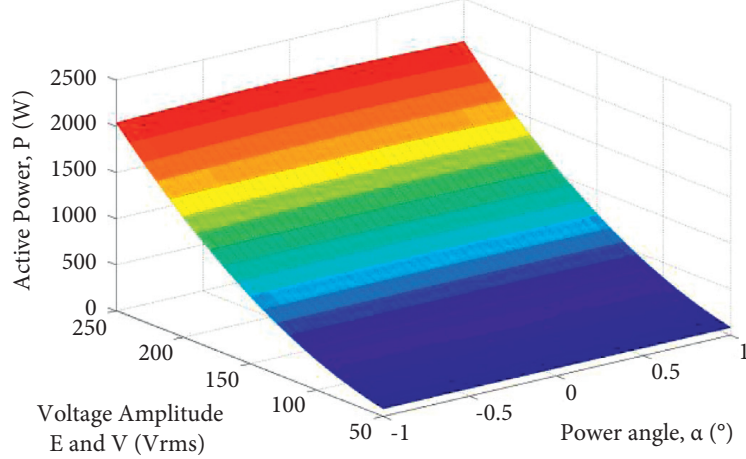

(c)

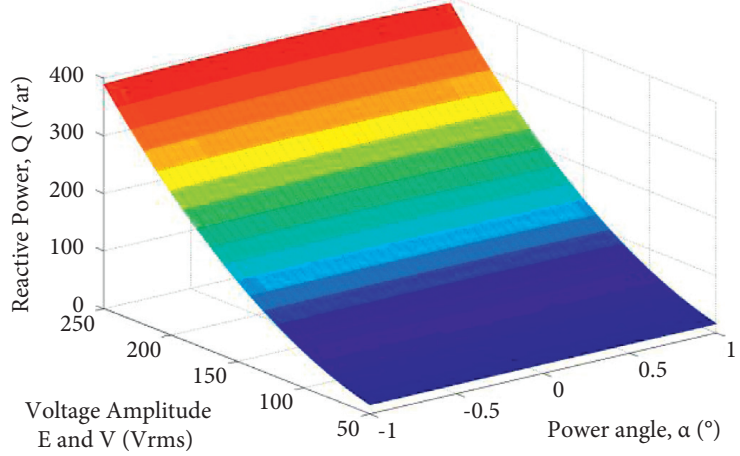

(b)

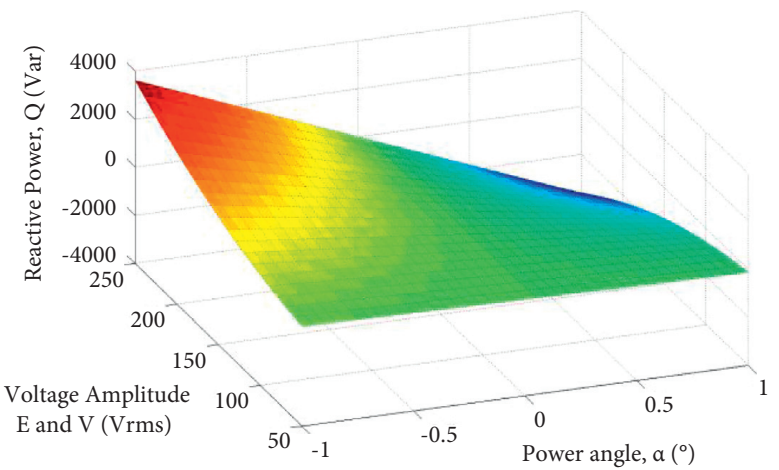

(d)

FIGURE 2: Active and reactive power coming from inverter at different voltage level when the voltage amplitude of inverter is same as voltage amplitude at the common AC bus and with the variation in power angle. (a) Active power plot under inductive line impedance. (b) Reactive power plot under inductive line impedance. (c) Active power plot under resistive line impedance. (d) Reactive power plot under resistive line impedance.

significant change in reactive power as power angle increases or decreases for all voltage levels, as shown in Figure 2(b). For resistive line impedance, change in power angle does not significantly affect inverter active power output; however, it varies the amount of reactive power inverter exchanges with the load. These observations can be seen in Figures 2(c) and 2(d).

On the one hand, when the power angle $\alpha$ is kept at $0^{\circ}$, changing the amplitude of inverter's voltage does not affect active power in the system with highly inductive line impedance and reactive power in resistive line impedance, as shown in Figures 3(a) and 3(d), respectively. On the other hand, increasing the amplitude of inverter's voltage increases reactive power for inductive line impedance and active power in resistive line impedance system and vice versa. This is applicable for all voltage levels, as shown in Figures 3(b) and 3(c).

\section{Principle of Proposed Semicentralized Power Sharing Scheme}

This section discusses the proposed power sharing technique, circuit configuration, synchronization technique, central controller, reference voltage adjustment, and communication structure.

3.1. Circuit Configuration. The parallel-connected inverter configuration used in this paper is shown in Figure 4(a). Each inverter module consists of a three-phase inverter, which is controlled using sinusoidal pulse width modulation (SPWM), output power filter, contactor, two voltage transducers, and interface inductor. The first voltage transducer is placed after the output power filter and 


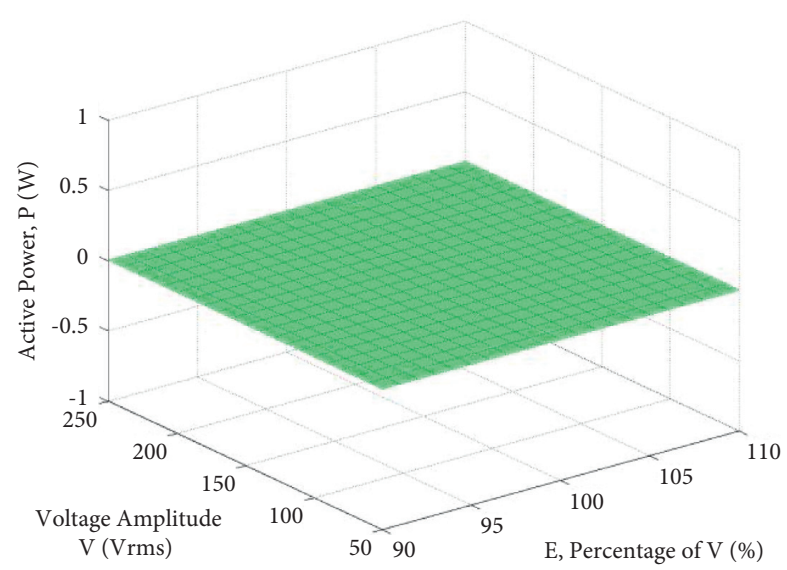

(a)

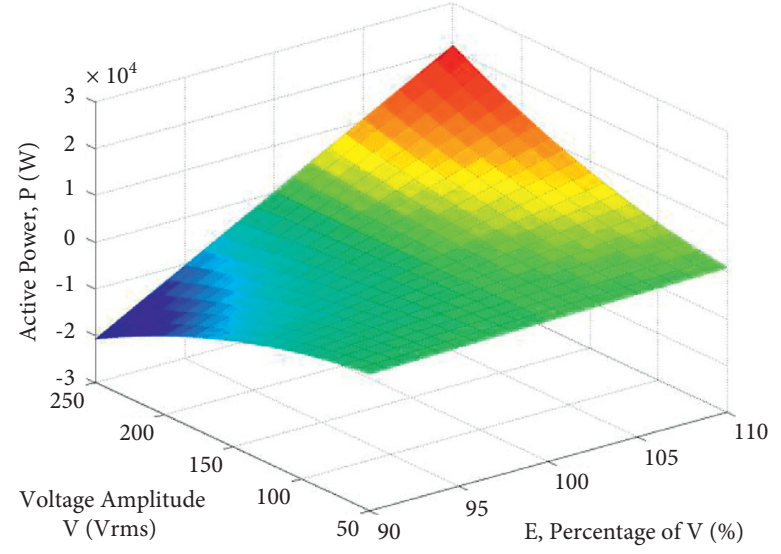

(c)

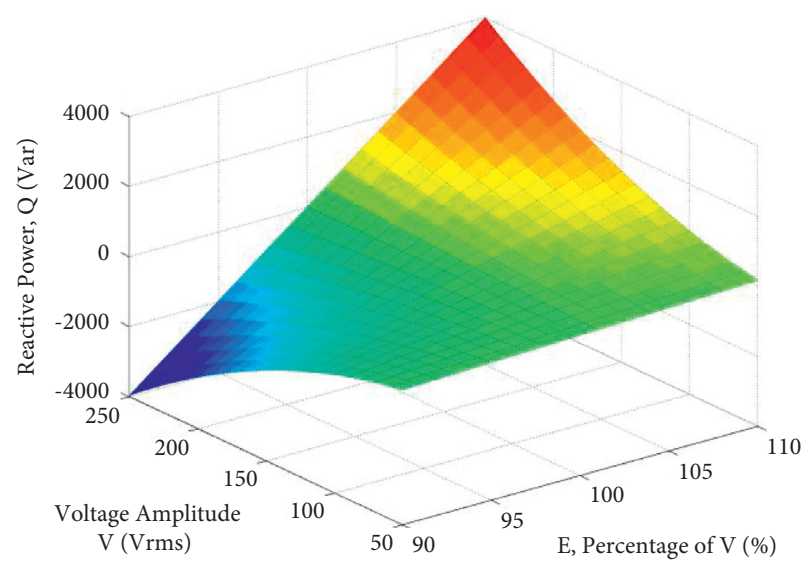

(b)

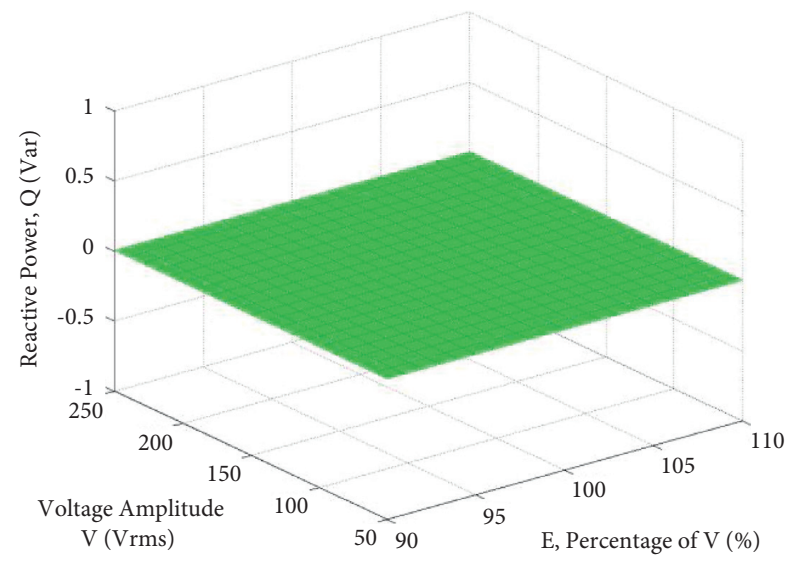

(d)

Figure 3: Active and reactive power coming from inverter at different voltage levels when the power angle is set to 0 and with the variation in amplitude of inverter's voltage. (a) Active power plot under inductive line impedance. (b) Reactive power plot under inductive line impedance. (c) Active power plot under resistive line impedance. (d) Reactive power plot under resistive line impedance.

followed by a contactor. This transducer measures the inverter's output voltage when it is connected to the microgrid. There is another voltage transducer placed after the contactor, which enables the inverter to measure $V_{p c c}$ prior and during the synchronization stage. Each inverter's output voltage is regulated by proportional integral (PI) controller in the DQ synchronous reference frame, as shown in Figure 4(b).

The interface inductor is needed to limit inrush current during inverter synchronization to the AC bus. This inductor dominates the overall line impedance; hence, the system becomes inductive. The central controller receives active and reactive power information from each inverter and calculates the active and reactive power references for each inverter. A low bandwidth communication is used to share the power information between different inverters. The details on communication are covered in Section 3.5.

3.2. Synchronization of Parallel Inverter. Synchronization with minimum errors in the phase and magnitude of the connecting inverter compared to those in operation is important for any proper transition from single inverter operation to parallel operation. Improper synchronization creates large inrush current at the moment of connection to the AC bus. There are several synchronization techniques discussed in the literature, and the majority use a digital phase locked loop (PLL) [27]. However, the proposed power sharing technique uses a zero-crossing technique presented in [28] for its simplicity and good performance in islanded microgrid.

In this approach, the zero-crossing detection method is used to synchronize connecting inverter's reference voltage frequency and phase to the voltage at the point of common coupling $\left(V_{p c c}\right)$. The first inverter establishes the voltage and frequency using internally generated reference voltage $V^{*}$ defined as follows:

$$
\begin{aligned}
V^{*}(k) & =E \sin \alpha(k), \\
\alpha(k) & =\alpha(k-1)+360 \cdot f \cdot T(k), \quad \text { if }\{\alpha(k) \geq 360\}, \\
\alpha(k) & =\alpha(k)-360, \\
T(k) & =\frac{1}{f_{s w}},
\end{aligned}
$$




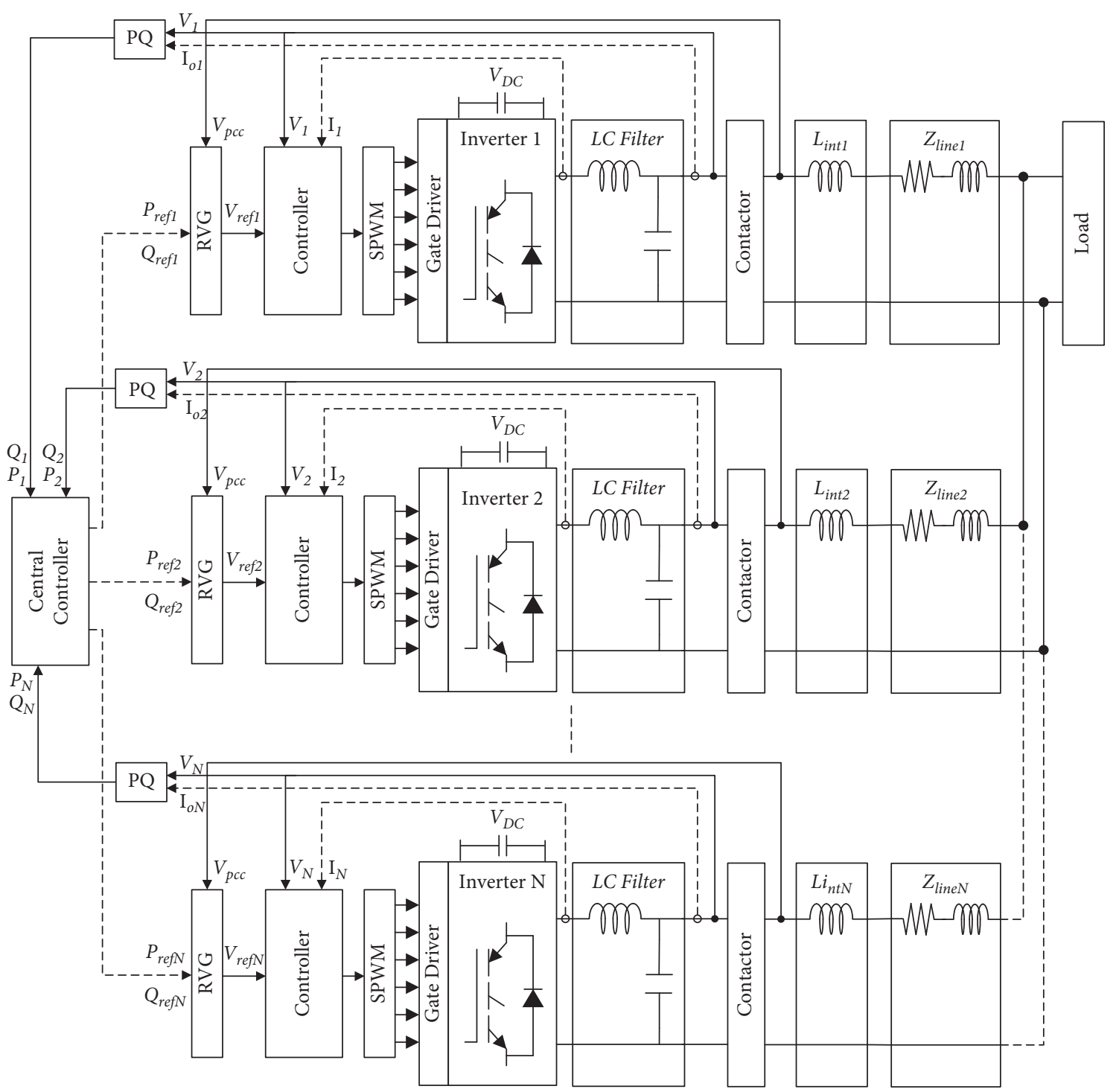

(a)

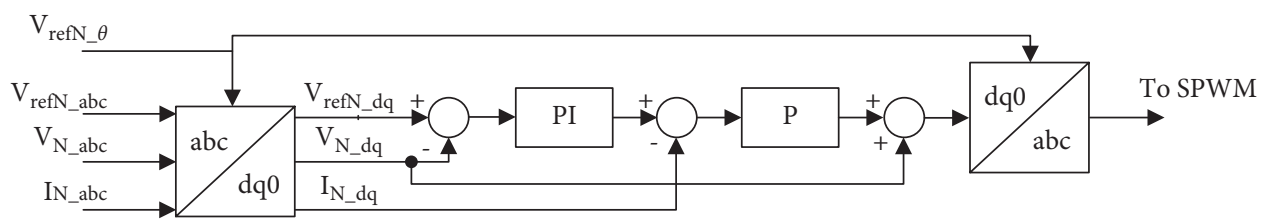

(b)

Figure 4: Parallel inverter configuration.

where $E$ is the preset amplitude, $\alpha(k)$ is the angle, $f$ is the system fundamental frequency, $T(k)$ is the switching period, and $f_{s w}$ is the switching frequency. During the synchronization of the subsequent inverter, each connecting inverter measures its $V_{p c c}$ and sends this information to its own reference voltage generator (RVG). RVG locates the zero crossing of $V_{p c c}$ and makes the adjustment to the $T(k)$ value through several reset-wait-measure-change procedural loops to adjust its reference voltage frequency to be the same as the frequency of $V_{p c c}$. When the frequency is synchronized, RVG resets the angle $\alpha(k)$ to 0 after detecting the next zero crossing to synchronize the phase of the connecting inverter to the phase of $V_{p c c}$.

3.3. Central Controller. The main function of the central controller is to generate the reference active and reactive powers for each inverter, taking the output active and reactive power information from each inverter at the previous sampling period. The central controller has the advantage of sharing the total active and reactive powers needed between the inverters by any arbitrary ratio that can be specified. 
Assuming $\mathrm{N}$ inverters are connected to the microgrid, the ratio for active power and reactive power is defined as follows:

$$
\begin{aligned}
& R_{P T}=\sum_{j=1}^{N} R_{P j}, \\
& R_{Q T}=\sum_{j=1}^{N} R_{Q j},
\end{aligned}
$$

where $R_{P j}$ and $R_{Q j}$ are the active and reactive power ratios set to $j^{\text {th }}$ inverter, respectively. The active and reactive power references for $j^{\text {th }}$ inverter are shown as

$$
\begin{gathered}
P_{j}^{*}(k)=\frac{R_{P j}}{R_{P T}} \sum_{h=1}^{N} P_{h}(k-1), \\
Q_{j}^{*}(k)=\frac{R_{Q j}}{R_{Q T}} \sum_{h=1}^{N} Q_{h}(k-1),
\end{gathered}
$$

where $P_{h}$ and $Q_{h}$ are the output active and reactive power from the $h^{\text {th }}$ inverter, respectively.

3.4. Reference Voltage Adjustment. When the RVG of an inverter receives the power references from the central controller, it calculates the active and reactive power differences. The active and reactive power differences of the $j^{\text {th }}$ inverter are given by

$$
\begin{gathered}
P_{\Delta j}(k)=P_{j}^{*}(k)-P_{j}(k-1), \\
Q_{\Delta j}(k)=Q_{j}^{*}(k)-Q_{j}(k-1) .
\end{gathered}
$$

From these power differences, the RVG makes adjustments to the reference voltage in order to force the inverter active and reactive output powers to follow their references. The voltage adjustment can be divided into two stages, which are the phase adjustment and amplitude adjustment. As stated earlier in this section, on the one hand, the system impedance is assumed to be dominated by inductive reactance, so the active power can be adjusted by varying the phase of reference voltage at the filter bus relative to that of the common AC bus. On the other hand, the reactive power can be changed by adjusting the amplitude of the reference voltage. There is no change in the frequency of the reference voltage. It is worth mentioning here that with the adjustment made by the controller, a consideration should be taken to compensate for the deviation to voltage, in particular, the amplitude. One way to compensate this is using a virtual impedance [29]. However, for the sake of simplification and highlighting the controller responses, the virtual impedance is neglected.

3.4.1. Phase Adjustment. The RVG monitors the $P_{\Delta j}$ and makes adjustment to its power angle $\alpha_{j}$ based on the following conditions:

$$
\begin{gathered}
\text { if }\left(P_{\Delta j}>P_{a j}\right) \\
\alpha_{j}(k)=\alpha_{j}(k-1)+\Delta \alpha_{x j}, \\
\text { if }\left(P_{b j}<P_{\Delta j} \leq P_{a j}\right) \\
\alpha_{j}(k)=\alpha_{j}(k-1)+\Delta \alpha_{y j}, \\
\text { if }\left(P_{c j}<P_{\Delta j} \leq P_{b j}\right) \\
\alpha_{j}(k)=\alpha_{j}(k-1)+\Delta \alpha_{z j}, \\
\text { if }\left(-P_{c j}<P_{\Delta j} \leq P_{c j}\right) \\
\alpha_{j}(k)=\alpha_{j}(k-1)+0, \\
\text { if }\left(-P_{b j}<P_{\Delta j} \leq-P_{c j}\right) \\
\alpha_{j}(k)=\alpha_{j}(k-1)-\Delta \alpha_{z j}, \\
\text { if }\left(-P_{a j}<P_{\Delta j} \leq-P_{b j}\right) \\
\alpha_{j}(k)=\alpha_{j}(k-1)-\Delta \alpha_{y j}, \\
\text { if }\left(P_{\Delta j} \leq-P_{a j}\right) \\
\alpha_{j}(k)=\alpha_{j}(k-1)-\Delta \alpha_{x j},
\end{gathered}
$$

where $P_{a j}, P_{b j}$, and $P_{c j}$ are the active power sublimits of $j^{\text {th }}$ inverter and $\Delta \alpha_{x j}, \Delta \alpha_{y j}$, and $\Delta \alpha_{z j}$ are the adjustment angles for $j^{\text {th }}$ inverter for every sampling time. The active power sublimits are defined as

$$
\begin{aligned}
& P_{a j}=\frac{1}{20} P_{j}^{0}, \\
& P_{b j}=\frac{1}{40} P_{j}^{0}, \\
& P_{c j}=\frac{1}{100} P_{j}^{0},
\end{aligned}
$$

where $P_{j}^{0}$ is the rated active power of $j^{\text {th }}$ inverter.

Figure 5(a) shows the time diagrams that will be used to assist in derivation of the expression for the adjustment angles used in the proposed power sharing. $\Delta P_{x j}, \Delta P_{y j}$, and $\Delta P_{z j}$ are the changes in $j^{\text {th }}$ inverter active power output as a result of different angle adjustments, $T_{d}$ is sampling period, and $T_{r}$ is the maximum time needed to change inverter output power from the initial operating condition to the desired new operating point. $T_{r}$ can be divided into three equally-divided sections with different levels of adjustment to the output power.

Assuming an inverter is just connected to microgrid and required to output its rated active power and the voltage magnitude at the filter bus and the common $\mathrm{AC}$ bus remain constant within each sampling period, the following proportional expression can be obtained as follows:

$$
\begin{aligned}
& \frac{\Delta P_{x j}}{T_{d}}=\frac{P_{j}^{0}-P_{a j}}{T_{a}}, \\
& \frac{\Delta P_{y j}}{T_{d}}=\frac{P_{a j}-P_{b j}}{T_{b}},
\end{aligned}
$$




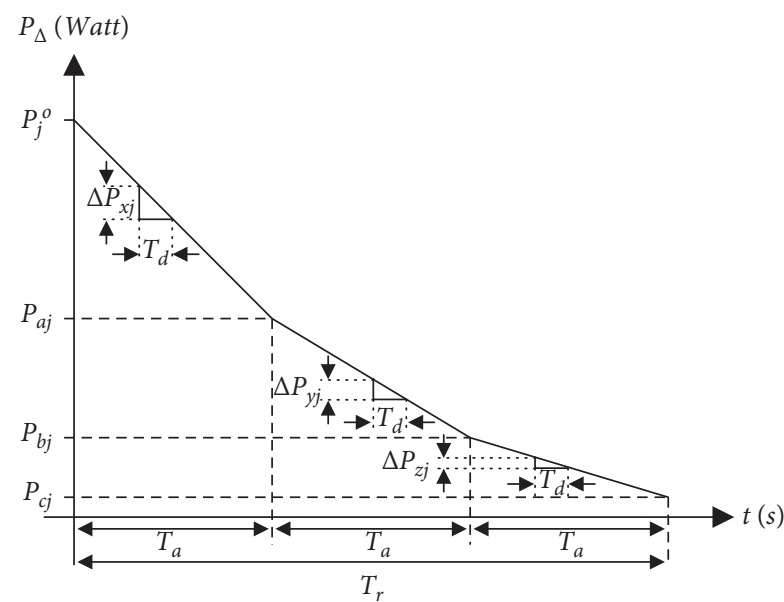

(a)

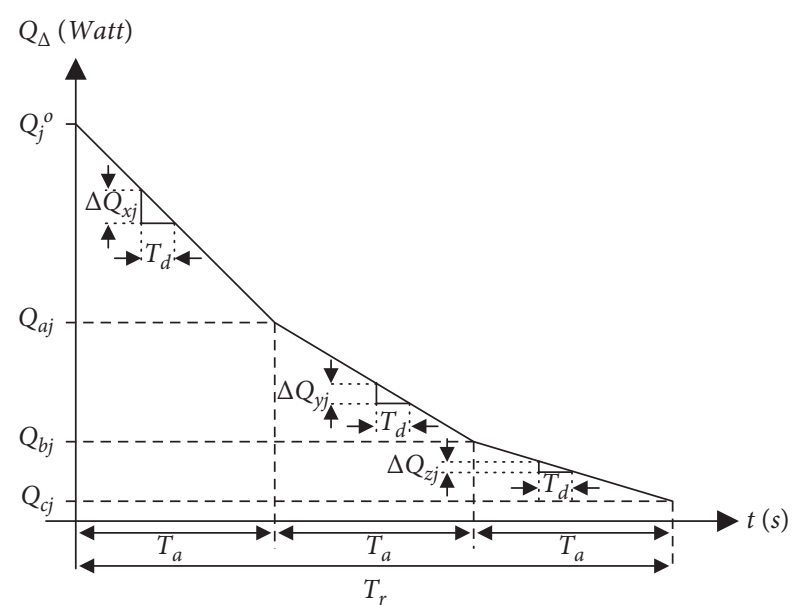

(b)

Figure 5: Time diagrams for the voltage adjustment parameters. (a) Phase adjustment and (b) amplitude adjustment.

$$
\frac{\Delta P_{z j}}{T_{d}}=\frac{P_{b j}-P_{c j}}{T_{c}} .
$$

The active power injected by an inverter into the common AC bus is rearranged as follows (with the assumption that $E \approx V$ ) to obtain the expression for the adjustment angle:

$$
\alpha=\sin ^{-1}\left[\frac{P X}{V^{2}}\right] .
$$

From this equation, the following expressions for adjustment angles can be obtained by replacing $\Delta P_{x}, \Delta P_{y}$, and $\Delta P_{z}$ from (8)-(10), respectively, into the $P$ term in (11).

$$
\begin{aligned}
& \Delta \alpha_{x j}=\sin ^{-1}\left[\frac{T_{d}}{T_{a}} \frac{\left(P_{j}^{0}-P_{a j}\right) X_{j}}{V_{j}^{2}}\right], \\
& \Delta \alpha_{y j}=\sin ^{-1}\left[\frac{T_{d}}{T_{a}} \frac{\left(P_{a j}-P_{b j}\right) X_{j}}{V_{j}^{2}}\right], \\
& \Delta \alpha_{z j}=\sin ^{-1}\left[\frac{T_{d}}{T_{a}} \frac{\left(P_{b j}-P_{c j}\right) X_{j}}{V_{j}^{2}}\right] .
\end{aligned}
$$

Adding or subtracting an adjustment value $\Delta \alpha_{x j}$ to the angle $\alpha_{j}$ produces rapid change in active power coming from the $j^{\text {th }}$ inverter, while adjustment values $\Delta \alpha_{y j}$ and $\Delta \alpha_{z j}$ produce relatively slower changes in active power. When $\left|P_{\Delta j}\right|$ is between $P_{b j}$ and $P_{c j}$, even slower adjustment is needed to avoid the fluctuation of active power output around the set point.

3.4.2. Amplitude Adjustment. The RVG also monitors $Q_{\Delta j}$ and makes adjustment to the reference voltage amplitude simultaneously as the load angle adjustment in the previous step. The adjustments to the amplitude of the reference voltage are based on the following conditions:

$$
\begin{gathered}
\text { if }\left(Q_{\Delta j}>Q_{a j}\right) \\
E_{j}(k)=E_{j}(k-1)+\Delta E_{x j}, \\
\text { if }\left(Q_{b j}<Q_{\Delta j} \leq Q_{a j}\right) \\
E_{j}(k)=E_{j}(k-1)+\Delta E_{y j}, \\
\text { if }\left(Q_{c j}<Q_{\Delta j} \leq Q_{b j}\right) \\
E_{j}(k)=E_{j}(k-1)+\Delta E_{z j}, \\
\text { if }\left(-Q_{c j}<Q_{\Delta j} \leq Q_{c j}\right) \\
E_{j}(k)=E_{j}(k-1)+0, \\
\text { if }\left(-Q_{b j}<Q_{\Delta j} \leq-Q_{c j}\right) \\
E_{j}(k)=E_{j}(k-1)-\Delta E_{z j}, \\
\text { if }\left(-Q_{a j}<Q_{\Delta j} \leq-Q_{b j}\right) \\
E_{j}(k)=E_{j}(k-1)-\Delta E_{y j}, \\
\text { if }\left(Q_{\Delta j} \leq-Q_{a j}\right) \\
E_{j}(k)=E_{j}(k-1)-\Delta E_{x j},
\end{gathered}
$$

where $Q_{a j}, Q_{b j}$, and $Q_{c j}$ are the active power limits of $j^{\text {th }}$ inverter and $\Delta E_{x j}, \Delta E_{y j}$, and $\Delta E_{z j}$ are the amplitude adjustments for $j^{\text {th }}$ inverter in every sampling time. The reactive power limits are defined as

$$
\begin{aligned}
& Q_{a j}=\frac{1}{20} Q_{j}^{0}, \\
& Q_{b j}=\frac{1}{40} Q_{j}^{0}, \\
& Q_{c j}=\frac{1}{100} Q_{j}^{0},
\end{aligned}
$$

where $Q_{j}^{0}$ is the rated reactive power of $j^{\text {th }}$ inverter.

Figure 5(b) shows the time diagrams that will be used to assist in derivation of the expression for the amplitude 
adjustments used in the proposed power sharing, and $\Delta Q_{x j}$, $\Delta Q_{y j}$, and $\Delta Q_{z j}$ are the changes in $j^{\text {th }}$ inverter reactive power output as a result of different amplitude adjustments.

Assuming an inverter is just connected to microgrid and required to output its rated reactive power, the following proportional expression can be obtained:

$$
\begin{gathered}
\frac{\Delta Q_{x j}}{T_{d}}=\frac{Q_{j}^{0}-Q_{a j}}{T_{a}}, \\
\frac{\Delta Q_{y j}}{T_{d}}=\frac{Q_{a j}-Q_{b j}}{T_{a}}, \\
\frac{\Delta Q_{z j}}{T_{d}}=\frac{Q_{b j}-Q_{c j}}{T_{a}} .
\end{gathered}
$$

The reactive power injected by an inverter into the common AC bus is rearranged as follows (with the assumption that $\alpha \approx 0$ ) to obtain the expression for the amplitude adjustments:

$$
E-V=Q \frac{X}{V}=\Delta E .
$$

From this equation, the following expressions for amplitude adjustments can be obtained by replacing $\Delta Q_{x}, \Delta Q_{y}$, and $\Delta Q_{z}$ from (17)-(19), respectively, into the $Q$ term in (20).

$$
\begin{aligned}
& \Delta E_{x j}=\left(Q_{j}^{0}-Q_{a j}\right) \frac{T_{d}}{T_{a}} \frac{X_{j}}{V_{j}}, \\
& \Delta E_{y j}=\left(Q_{a j}-Q_{b j}\right) \frac{T_{d}}{T_{a}} \frac{X_{j}}{V_{j}}, \\
& \Delta E_{z j}=\left(Q_{b j}-Q_{c j}\right) \frac{T_{d}}{T_{a}} \frac{X_{j}}{V_{j}} .
\end{aligned}
$$

The summarized reference voltage adjustment steps by the RVG are shown in Figure 6.

3.5. Communication Structure. This control technique required a low-bandwidth communication for the active and reactive power information exchange between each inverter and the central controller. The communication type may vary depending on inverter locations in the system and available communication structure. For example, in rural areas, company intranet and dedicated website can be used for communication, as proposed in [16]. If the inverters are located in the same building but separate far away from each other, the local area network communication can be used [15].

The experimental works presented in this paper use communication based on PWM signals outputted by each DSP and converted back to DC value at the target destination using low pass filters. The PWM frequency used for the communication is $10 \mathrm{kHz}$, which is higher than switching frequency used for the inverter control $(4.2 \mathrm{kHz})$. This high frequency is adopted so that a small filter size can be used to filter out the PWM signal.

\section{Stability Analysis of the Proposed Power Sharing Technique}

A small signal model has been developed for the proposed power sharing technique to assess its stability against the controller parameters and the chosen power ratio. The small signal model represents multiparallel inverters connected to the PCC with a shared load. As the voltage controller for each inverter has been implemented in the DQ frame, the output impedance ideally equals zero as the internal model principal states [30]. Therefore, the grid-side impedance $\left(L_{\text {int }, j}\right)$ will represent the final output impedance for each inverter. A thevenin equivalent for each inverter is used [31] for simplicity as the most major dynamics are dominated by the low frequency modes of power sharing loops [32]. Figure 7 shows the small signal model of the microgrid including the proposed controller.

The power control loop gathers the power information from all inverters and then produces a set point for each inverter. The equivalent instantaneous power equals the load power which can be calculated in the DQ frame by

$$
\begin{aligned}
& p_{\text {Lins }}=\frac{3}{2}\left(v_{L d} i_{L d}+v_{L q} i_{L q}\right), \\
& q_{\text {Lins }}=\frac{3}{2}\left(v_{L d} i_{L q}-v_{L q} i_{L d}\right) .
\end{aligned}
$$

The average load power is obtained after passing the instantaneous power through a low pass filter as

$$
\begin{aligned}
P_{T} & =\frac{\omega_{c}}{s+\omega_{c}} p_{\text {Lins }}, \\
Q_{T} & =\frac{\omega_{c}}{s+\omega_{c}} q_{\text {Lins }},
\end{aligned}
$$

where $P_{T}$ and $Q_{T}$ are the averaged total power from all inverters and $\omega_{c}$ is the cutoff frequency of the low pass filter.

Each inverter receives its power set point, and then the required phase angle is calculated as in (12)-(14). Therefore, the phase of each inverter can be obtained as

$$
\begin{aligned}
& \alpha_{j}=m_{j} P_{T}, \\
& m_{j}=\frac{T_{d}}{T_{a}} \frac{X_{j}}{V_{j}^{2}} \frac{R_{P j}}{R_{P T}},
\end{aligned}
$$

where $m_{j}$ is the active power-phase gain for the $j^{\text {th }}$ inverter. In the same way, the amplitude is obtained by

$$
\begin{aligned}
\Delta E_{j} & =n_{j} Q_{T}, \\
n_{j} & =\frac{T_{d}}{T_{a}} \frac{X_{j}}{V_{j}} \frac{R_{Q j}}{R_{Q T}},
\end{aligned}
$$

where $n_{j}$ is the reactive power-amplitude gain for the $j^{\text {th }}$ inverter. By linearizing equations (23)-(25), the central control loop is derived as 


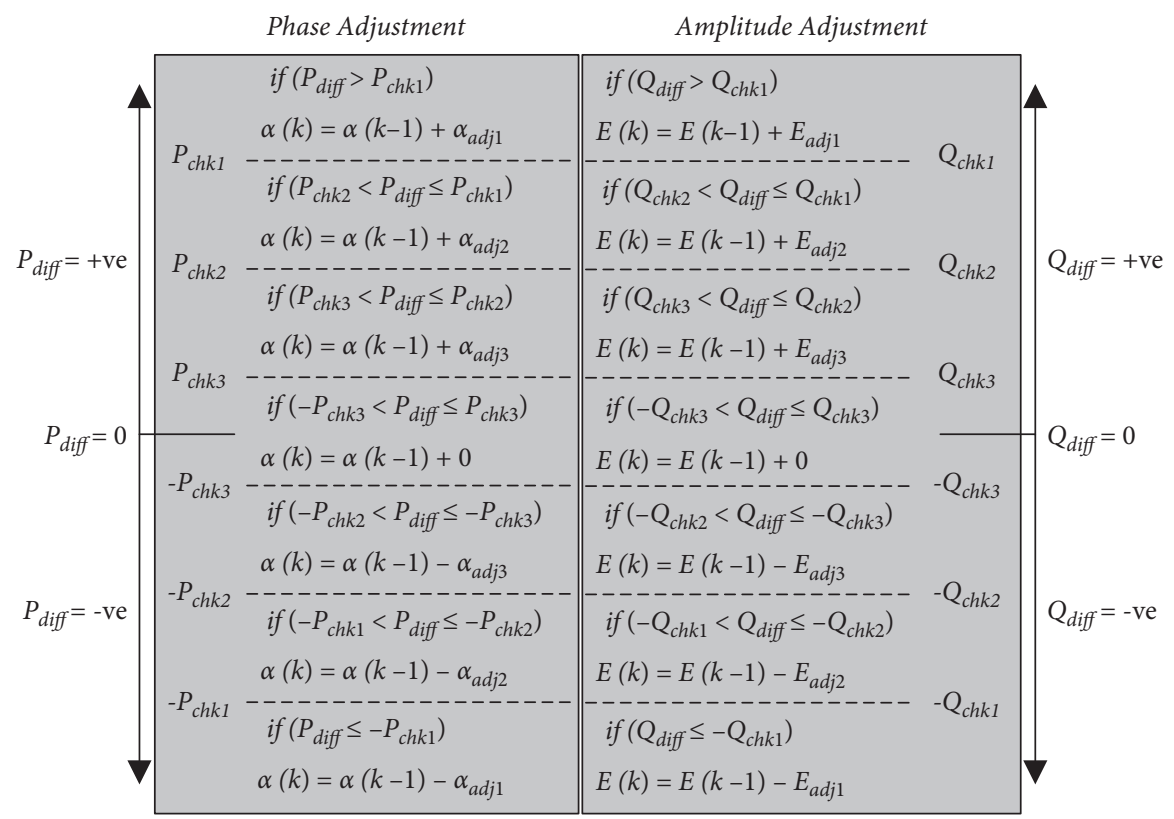

Figure 6: Illustration of the steps needed for simultaneous adjustment of the phase and amplitude of the inverter reference voltage.

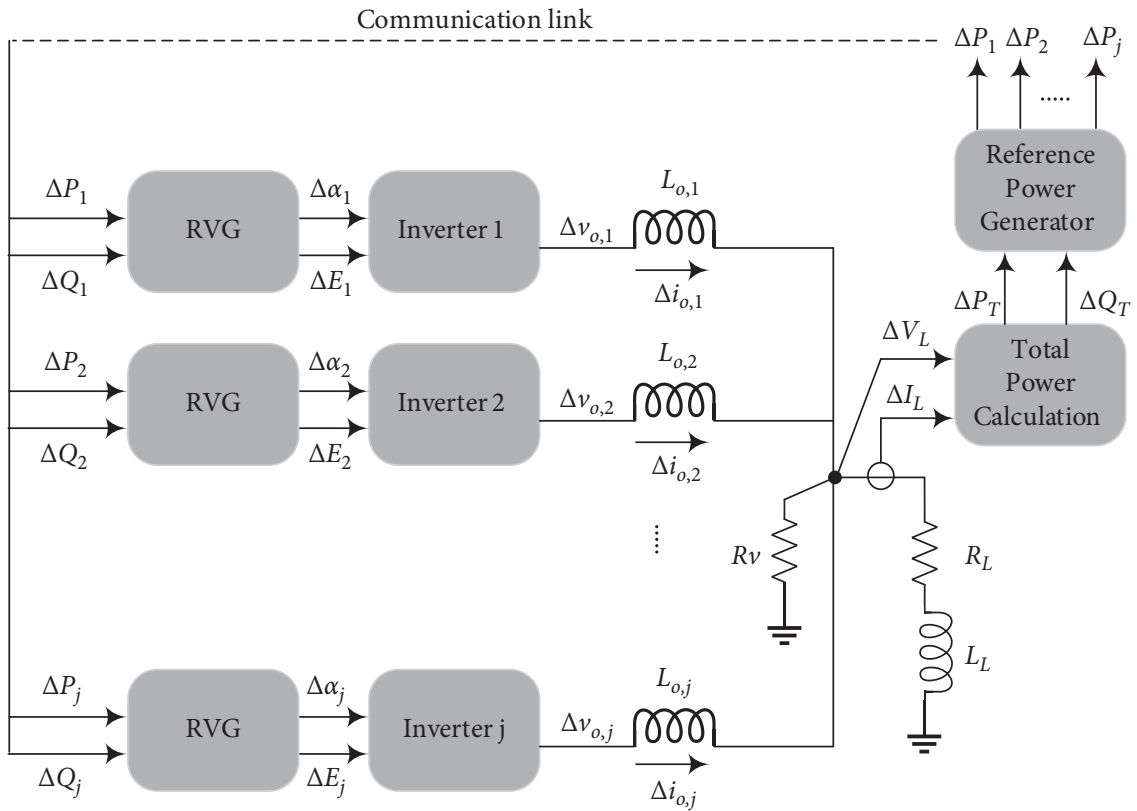

Figure 7: Small signal model of the microgrid including the proposed controller. 


$$
\begin{aligned}
{\left[\begin{array}{c}
\Delta \dot{P}_{T} \\
\Delta Q_{T}
\end{array}\right] } & =A_{P}\left[\begin{array}{c}
\Delta P_{T} \\
\Delta Q_{T}
\end{array}\right]+B_{v}\left[\begin{array}{c}
\Delta v_{L D} \\
\Delta v_{L Q}
\end{array}\right]+B_{i}\left[\begin{array}{c}
\Delta i_{L D} \\
\Delta i_{L Q}
\end{array}\right], \\
{\left[\begin{array}{c}
\Delta \alpha_{j}
\end{array}\right] } & =C_{a, j}\left[\begin{array}{c}
\Delta P_{T} \\
\Delta Q_{T}
\end{array}\right], \\
{\left[\begin{array}{c}
\Delta v_{o d, j} \\
\Delta v_{o q, j}
\end{array}\right] } & =C_{v, j}\left[\begin{array}{c}
\Delta P_{T} \\
\Delta Q_{T}
\end{array}\right], \\
\text { where } & \\
A_{P}= & {\left[\begin{array}{cc}
-\omega_{c} & 0 \\
0 & -\omega_{c}
\end{array}\right], } \\
B_{v} & =\left[\begin{array}{cc}
1.5 \omega_{c} \cdot I_{L D} & 1.5 \omega_{c} \cdot I_{L Q} \\
1.5 \omega_{c} \cdot I_{L Q} & -1.5 \omega_{c} \cdot I_{L D}
\end{array}\right], \\
B_{i} & =\left[\begin{array}{cc}
1.5 \omega_{c} \cdot V_{L D} & 1.5 \omega_{c} \cdot V_{L Q} \\
-1.5 \omega_{c} \cdot V_{L Q} & 1.5 \omega_{c} \cdot V_{L D}
\end{array}\right], \\
C_{a, j} & =\left[\begin{array}{ll}
m_{j} & 0
\end{array}\right] \\
C_{v, j} & =\left[\begin{array}{ll}
0 & n_{j} \\
0 & 0
\end{array}\right],
\end{aligned}
$$

where the capital letter notations $\left(I_{L D}, I_{L Q}, V_{L D}, V_{L Q}\right)$ denote the steady state values which can be obtained by MATLAB/Simulink simulation of the model. The state of the output current for each inverter can be modeled as

$$
\begin{aligned}
& {\left[\begin{array}{c}
\Delta i_{o d, j} \\
\Delta i_{o q, j}
\end{array}\right]=A_{Z, j}\left[\begin{array}{c}
\Delta i_{o d, j} \\
\Delta i_{o q, j}
\end{array}\right]+B_{Z 1, j}\left[\begin{array}{c}
\Delta v_{o d} \\
\Delta v_{o q}
\end{array}\right]+B_{Z 2, j}\left[\begin{array}{c}
\Delta v_{L d} \\
\Delta v_{L q}
\end{array}\right],} \\
& A_{Z, j}=\left[\begin{array}{cc}
-\frac{R_{o, j}}{L_{o, j}} & \omega_{o} \\
-\omega_{o} & -\frac{R_{o, j}}{L_{o, j}}
\end{array}\right], \\
& B_{Z 1, j}=\left[\begin{array}{ccc}
I_{o q, j} & \frac{1}{L_{o, j}} & 0 \\
-I_{o d, j} & 0 & \frac{1}{L_{o, j}}
\end{array}\right] \text {, } \\
& B_{Z 2, j}=\left[\begin{array}{cc}
\frac{-1}{L_{o, j}} & 0 \\
0 & \frac{-1}{L_{o, j}}
\end{array}\right] \text {. }
\end{aligned}
$$

Because the load states are in the common DQ frame which are obtained by the common bus frequency and phase, each inverter state has to be transformed to the common DQ frame instead of its local DQ frame. Thus, inverter 1 frame can be chosen as the common, and all states should be represented by the same transformation to the common frame. The mapping matrices for the states $i_{o d q, j}$ to $i_{o D Q, j}$ are calculated as

$$
\begin{aligned}
{\left[\begin{array}{c}
\Delta i_{o D, j} \\
\Delta i_{o Q, j}
\end{array}\right] } & =C_{M i, j}\left[\Delta \alpha_{\mathrm{com}}\right]+D_{M i, j}\left[\begin{array}{c}
\Delta i_{o d, j} \\
\Delta i_{o q, j}
\end{array}\right], \\
C_{M i, j} & =\left[\begin{array}{cc}
-I_{o d, j} \cdot \sin \left(\alpha_{o}\right)-I_{o q \cdot} \cdot \cos \left(\alpha_{o}\right) \\
I_{o d, j} \cdot \cos \left(\alpha_{o}\right)-I_{o q} \cdot \sin \left(\alpha_{o}\right)
\end{array}\right], \\
D_{M i, j} & =\left[\begin{array}{cc}
\cos \left(\alpha_{o}\right) & -\sin \left(\alpha_{o}\right) \\
\sin \left(\alpha_{o}\right) & \cos \left(\alpha_{o}\right)
\end{array}\right] .
\end{aligned}
$$

The common phase angle $\Delta \alpha_{\text {com }}$ equals $\Delta \alpha_{1}$ for our assumption.

In the same manner, the state of the load voltage can be transformed to the local frame which is used in (28) by

$$
\begin{aligned}
{\left[\begin{array}{c}
\Delta v_{L d} \\
\Delta v_{L q}
\end{array}\right] } & =C_{M v}\left[\Delta \alpha_{\mathrm{com}}\right]+D_{M v}\left[\begin{array}{c}
\Delta v_{L D} \\
\Delta v_{L Q}
\end{array}\right] \\
C_{M v} & =\left[\begin{array}{cc}
-V_{L D} \cdot \sin \left(\alpha_{o}\right)+V_{L Q} \cdot \cos \left(\alpha_{o}\right) \\
-V_{L D} \cdot \cos \left(\alpha_{o}\right)-V_{L Q} \cdot \sin \left(\alpha_{o}\right)
\end{array}\right], \\
D_{M v} & =\left[\begin{array}{cc}
\cos \left(\delta_{o}\right) & \sin \left(\delta_{o}\right) \\
-\sin \left(\delta_{o}\right) & \cos \left(\delta_{o}\right)
\end{array}\right]
\end{aligned}
$$

Each inverter, $j$, now can be modeled as a subsystem of the entire model as

$$
\begin{aligned}
{\left[\begin{array}{c}
\Delta i_{o d, j} \\
\Delta i_{o q, j}
\end{array}\right] } & =A_{i n v Z, j}\left[\begin{array}{c}
\Delta i_{o d, j} \\
\Delta i_{o q, j}
\end{array}\right]+B_{i n v P, j}\left[\begin{array}{c}
\Delta v_{o d} \\
\Delta v_{o q}
\end{array}\right]+B_{i n v V, j}\left[\begin{array}{c}
\Delta v_{L d} \\
\Delta v_{L q}
\end{array}\right], \\
\text { where } & \\
A_{i n v Z, j} & =A_{Z, j}, \\
B_{i n v P, j} & =B_{Z 1, j} \cdot C_{v, j}+B_{Z 2, j} \cdot C_{M v} \cdot C_{a c o m} \\
B_{i n v V, j} & =B_{Z 2, j} \cdot D_{M v} .
\end{aligned}
$$

For the sake of the entire microgrid model development, the states of the inverter's output currents in (30) can be all combined together as 


$$
\begin{aligned}
{\left[\begin{array}{c}
\Delta i_{o d q, 1} \\
\Delta i_{o d q, 2}
\end{array}\right] } & =A_{I N V}\left[\begin{array}{c}
\Delta i_{o d q, 1} \\
\Delta i_{o d q, 2} \\
\cdot
\end{array}\right]+B_{I N V P}\left[\begin{array}{c}
\Delta P_{T} \\
\Delta Q_{T}
\end{array}\right]+B_{I N V V}\left[\begin{array}{c}
\Delta v_{L d} \\
\Delta v_{L q}
\end{array}\right], \\
A_{I N V} & =\left[\begin{array}{ccc}
A_{i n v z, 1} & 0 & 0 \\
0 & A_{i n v z, 2} & 0 \\
0 & 0 & .
\end{array}\right], \\
B_{I N V P} & =\left[\begin{array}{c}
B_{i n v P, 1} \\
B_{i n v P, 2} \\
\cdot
\end{array}\right], \\
B_{I N V V} & =\left[\begin{array}{c}
B_{i n v V, 1} \\
B_{i n V V, 2} \\
\cdot
\end{array}\right] .
\end{aligned}
$$

Finally, the state of the load connected to the PCC represented by the load current state is derived as

$$
\begin{aligned}
{\left[\begin{array}{c}
\Delta i_{L D} \\
\Delta i_{L Q}
\end{array}\right] } & =A_{L}\left[\begin{array}{c}
\Delta i_{L D} \\
\Delta i_{L Q}
\end{array}\right]+B_{L}\left[\begin{array}{c}
\Delta v_{L D} \\
\Delta v_{L Q}
\end{array}\right] \\
A_{L} & =\left[\begin{array}{cc}
\frac{-R_{L}}{L_{L}} & \omega_{o} \\
\omega_{o} & \frac{-R_{L}}{L_{L}}
\end{array}\right], \\
B_{L} & =\left[\begin{array}{cc}
\frac{1}{L_{L}} & 0 \\
0 & \frac{1}{L_{L}}
\end{array}\right] .
\end{aligned}
$$

It is clear that the load voltage is treated as input to some subsystems. To close the loop, the load voltage $\Delta v_{L D Q}$ has to be defined in terms of the available states. The virtual resistor method is used to ease the derivation. A virtual resistor $R_{v}$ with a high value $(1000 \Omega)$ is assumed to be connected to the PCC. This resistor has a negligible impact on the system dynamics [33]. Consequently, the $\Delta v_{L D Q}$ is calculated as

$$
\begin{gathered}
\text { where } \\
C_{v L R}=R_{v}\left[\begin{array}{llllll}
1 & 0 & 1 & 0 & . \\
0 & 1 & 0 & 1 & . & .
\end{array}\right], \\
C_{v i L}=R_{v}\left[\begin{array}{ccc}
-1 & 0 \\
0 & -1
\end{array}\right] .
\end{gathered}
$$$$
\left[\Delta v_{L D Q}\right]=C_{v L R \cdot} \cdot\left[\begin{array}{c}
\Delta i_{o D Q, 1} \\
\Delta i_{o D Q, 2} \\
.
\end{array}\right]+C_{v i L} \cdot\left[\Delta i_{L D Q}\right],
$$

By rearranging (33),

$$
\begin{gathered}
\text { where } \\
C_{v L i}=C_{v L R \cdot} \cdot\left[\begin{array}{ccc}
D_{M i, 1} & 0 & 0 \\
0 & D_{M i, 2} & 0 \\
0 & 0 & .
\end{array}\right], \\
C_{v L P}=C_{v L R} \cdot\left[\begin{array}{c}
C_{M i, 1} \cdot C_{\mathrm{acom}} \\
C_{M i, 2} \cdot C_{\mathrm{acom}} \\
\cdot
\end{array}\right]
\end{gathered}
$$

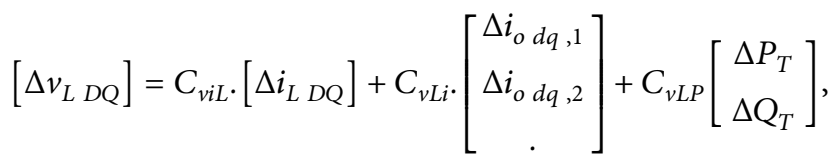

The entire microgrid model including the proposed control scheme is obtained as

$$
\dot{x}=A_{m g} x,
$$

where

$$
\begin{aligned}
A_{m g} & =\left[\begin{array}{ccc}
A_{P}+B_{v} \cdot C_{v L P} & B_{v} \cdot C_{v L i} & B_{i}+B_{v} \cdot C_{v i L} \\
B_{I N V P}+B_{I N V V} \cdot C_{v L P} & A_{I N V}+B_{I N V V} \cdot C_{v L i} & B_{I N V V} \cdot C_{v i L} \\
B_{L} \cdot C_{v L P} & B_{L} \cdot C_{v L i} & A_{L}+B_{L} \cdot C_{v i L}
\end{array}\right], \\
x & =\left[\begin{array}{ccc}
\underbrace{\Delta P_{T} \Delta \mathrm{Q}_{T}}_{\text {Central Controller States }} & \underbrace{\Delta i_{o d q, 1}, \Delta i_{o d q, 2}, \Delta i_{o d q, 3}, \ldots}_{\text {Inverters output current states }} & \underbrace{\Delta i_{L D Q}}_{\text {Load current state }}
\end{array}\right] .
\end{aligned}
$$

Equations (24) and (25) include the parameters of the proposed controller which are $T_{d}, T_{a}, R_{P j}, R_{P T}$, $R_{\mathrm{Qj}}$, and $R_{\mathrm{QT}}$, while $X_{j}$ and $V_{j}$ are assumed to be fixed variable. For a distribution ratio of $1: 1: 1$, Figure 8 shows the root locus of the system when $\left(T_{a} / 100\right)<T_{d}<$ $\left(T_{a} / 2\right)$ and $T_{a}=100 \mathrm{~ms}$. It is obvious that variations of $T_{d}$ have no significant effect on the system dynamics. The dominant poles (on the right) are controlled by the output impedance values and the low pass filter cutoff frequency.

Figure 9 shows the low frequency pole evolution when the low pass filter cutoff frequency varies as $1<\omega_{c}<300 \mathrm{rad} / \mathrm{s}$. The oscillatory poles become dominant for a high bandwidth filter. The effect of varying the output impedances on the root locus is shown in Figure 10 where 


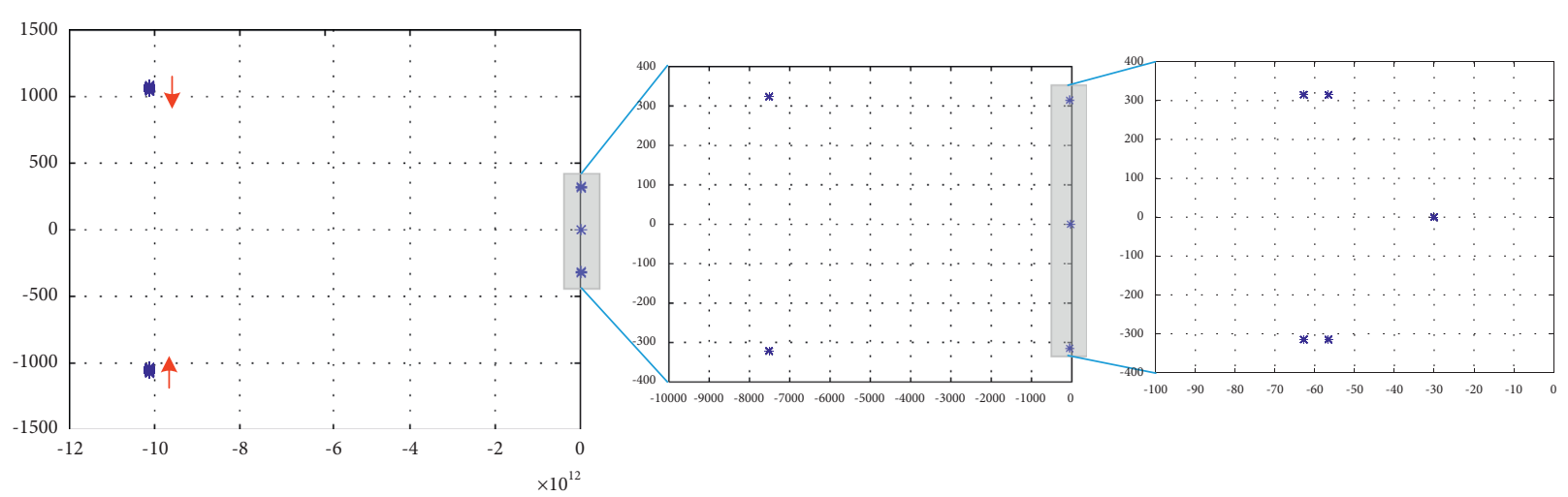

FIGURE 8: Root locus of the system when $\left(T_{a} / 100\right)<T_{d}<\left(T_{a} / 2\right)$ and $T_{a}=100 \mathrm{~ms}$.

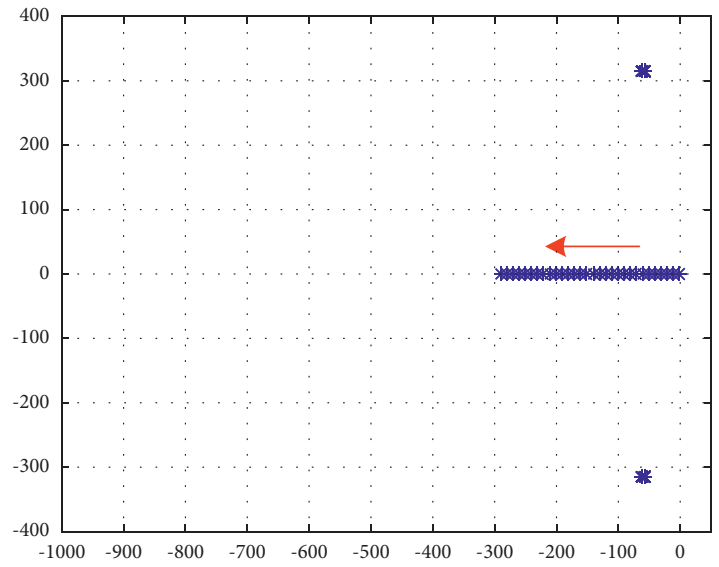

Figure 9: Root locus of the system when the low pass filter cutoff frequency varies as $1<\omega_{c}<300 \mathrm{rad} / \mathrm{s}$.

the output inductance of the first inverter changes as $0.5 \mathrm{mH}<L_{o, 1}<30 \mathrm{mH}$, while the others are the same as in Table 1. As the output impedance and the cut off frequency are fixed in the design phase, the dynamics of the system, regardless of the ratio among inverters and the controller response time, and assure the stability.

\section{Results and Discussion: Simulation Analysis}

This section presents MATLAB/Simulink simulations that aim to validate the performance of the proposed power sharing scheme. The proposed scheme is validated on a microgrid, as shown in Figure 4(a) that comprises of three parallel inverters and loads, with parameters listed in Table 1. The simulation results are divided into two parts. Part I compares the dynamic performance of the proposed power sharing scheme to that of the conventional droop control under similar operating conditions. Additionally, the robustness of the proposed controller to the impedance mismatch is investigated by using unequal interfacing inductors for all inverters. A delay of $5 \mathrm{~ms}$ is added to the information exchange between inverters and the central controller to consider the effect of communication delay in real world application. Part II presents the performance of the proposed power sharing scheme with different power ratios assigned to each inverter.
In both parts, initially, inverter 1 output voltage is ramped up to its rated voltage and connected to load 1 (all the power is provided by inverter 1 ). At time $t=100 \mathrm{~ms}$, a second inverter is connected to the microgrid followed by the third inverter at $t=400 \mathrm{~ms}$. The load 1 is disconnected at $t=1.0 \mathrm{~s}$ and reconnected at $t=1.2 \mathrm{~s}$. At $t=1.6 \mathrm{~s}$, the additional load (load 2) is added to load 1.

5.1. Simulation Part I. In this part, all the three inverters share the total load power by the ratio of $1: 1: 1$. Figure 11 presents simulation results that compare the proposed power sharing scheme to that of the conventional droop technique. It is important to mention that a discrete loading is applied at the beginning of simulation to expose the proposed controller action and performance and then followed by a significant load step. The initial load was $420 \mathrm{~W}$ and after reaching the steady state, the load was disconnected, and the second step was to $1350 \mathrm{~W}$.

Figure 11(a) presents current contributions of the three inverters and total load current waveform using the proposed power sharing scheme, while the current waveforms obtained using conventional droop are presented in Figure 11(b). These results have shown that both control schemes are able to share the total load between the three inverters but with different dynamic responses.

Figures 11(c) and 11(d) show the active and reactive power output of three inverters and the total load active and reactive powers using the proposed power sharing technique and the droop control, respectively. It can be observed that the proposed power sharing scheme has faster dynamic response compared to that of the conventional droop control as it takes less than $100 \mathrm{~ms}$ to equally share the active and reactive powers between the three inverters. Also, the proposed power scheme exhibits lower circulating currents between the inverters than the conventional droop control. When the second load is connected at $t=1.6 \mathrm{~s}$, good transient and steady state performances are observed. Figure 11(d) has shown that the droop control has slower dynamic response and takes longer period for the inverters to achieve equal active power sharing, while it is unable to achieve equal reactive power sharing. This is because the conventional droop control is sensitive to impedance mismatch. 

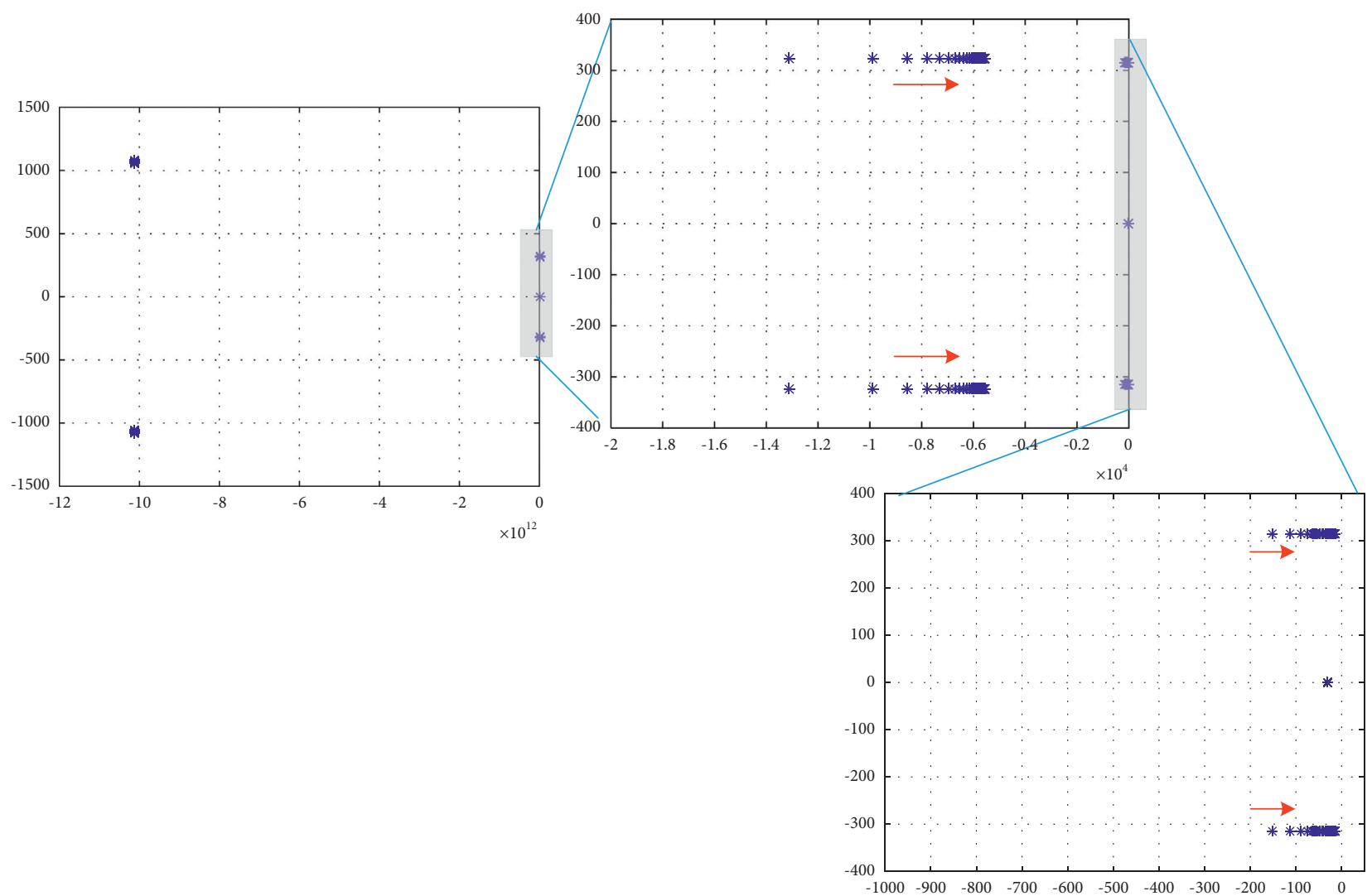

FIgURE 10: Root locus of the system when the output inductance of the first inverter changes as $0.5 \mathrm{mH}<L_{o, 1}<30 \mathrm{mH}$.

TABLE 1: System parameters.

\begin{tabular}{lcc}
\hline Description & Symbol & Value \\
\hline DC link voltage & $V_{D C}$ & $150 \mathrm{~V}$ \\
Reference voltage & $V_{\text {ref }}$ & $60 \mathrm{~V}(\mathrm{peak})$ \\
Switching frequency & $f_{s w}$ & $4.2 \mathrm{kHz}$ \\
System frequency & $f$ & $50 \mathrm{~Hz}$ \\
Sampling period & $T_{d}$ & $5 \mathrm{~ms}$ \\
Max power adjustment time & $T_{r}$ & $300 \mathrm{~ms}$ \\
Filter inductance (all) & $L_{f}$ \\
Filter capacitance (all) & $C_{f}$ & $2 \mathrm{mH}$ \\
Interface inductance 1 & $L_{\text {int1 }}$ & $30 \mu \mathrm{F}$ \\
Interface inductance 2 & $L_{\text {int2 }}$ & $5 \mathrm{mH}$ \\
Interface inductance 3 & $L_{\text {int3 }}$ \\
Line impedance 1 & $Z_{\text {line1 }}$ \\
Line impedance 2 & $Z_{\text {line2 }}$ \\
Line impedance 3 & $Z_{\text {line3 }}$ \\
Load 1 & $R_{\text {load1 }}$ \\
Load 2 & $R_{\text {load2 }}$ & $3.75 \mathrm{mH}$ \\
Nonlinear load & $R n l$ & $6.2 \mathrm{mH}$ \\
Inverter 1 rating & & $0.3 \Omega$ \\
Inverter 2 rating & & $0.2 \Omega$ \\
Inverter 3 rating & & $0.4 \Omega$ \\
Part I-active power ratio & & $12 \Omega$ \\
Part I-reactive power ratio & & $5.6 \Omega$ \\
Part II-active power ratio & $R P 1: R P 2: R P 3$ \\
Part II-reactive power ratio & $R Q 1: R Q 2: R Q 3$ & 30 \\
\hline
\end{tabular}




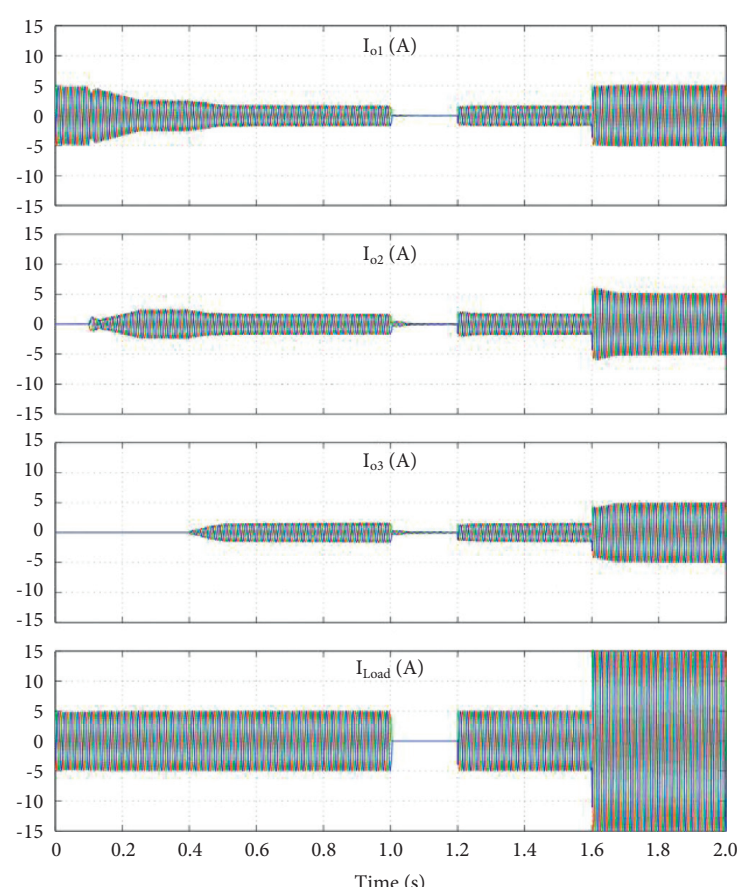

(a)
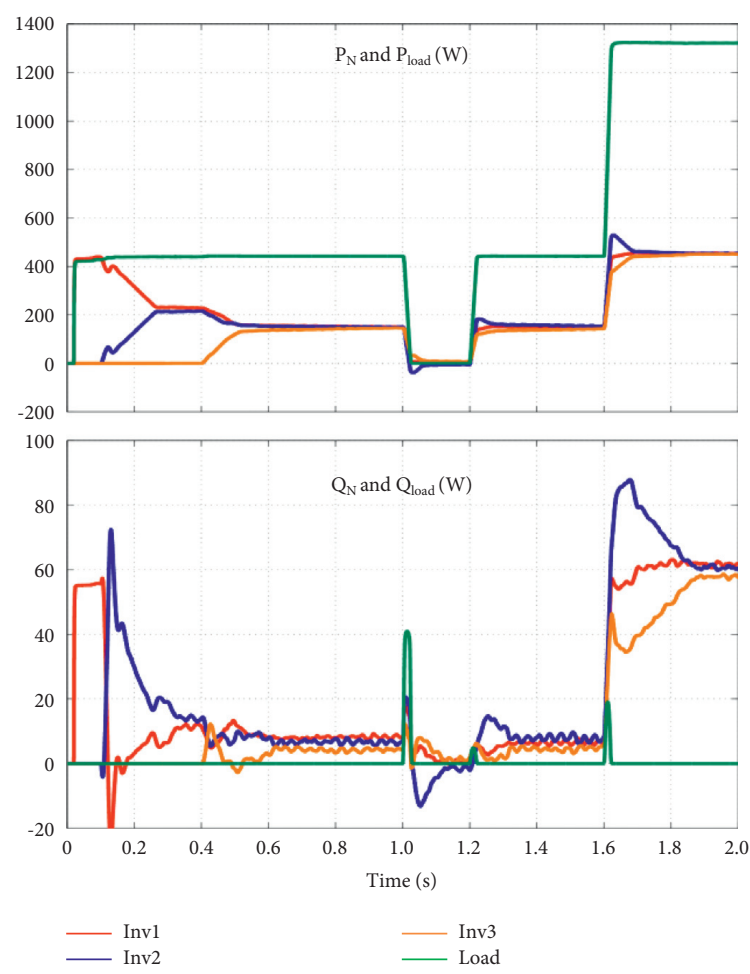

(c)

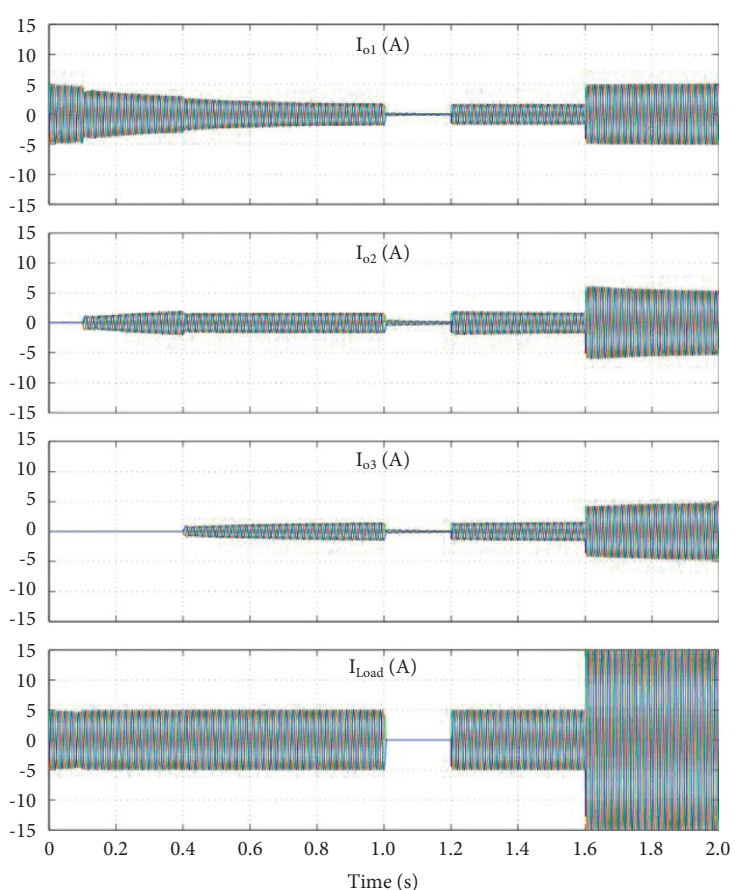

(b)
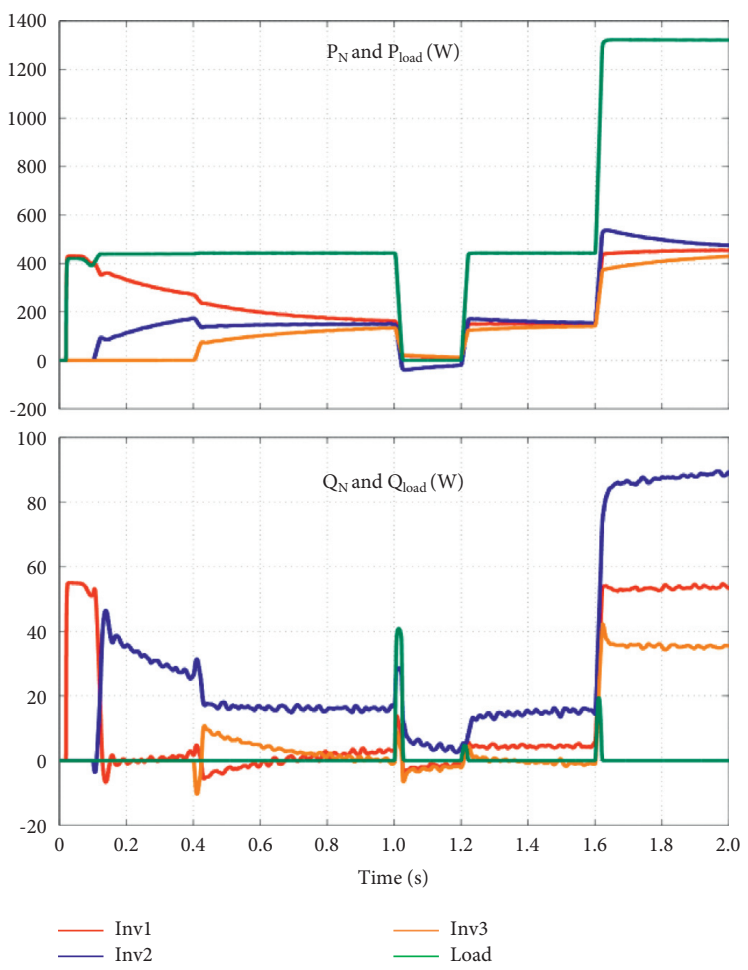

(d)

Figure 11: Simulation results for part I. (a) Output current and load current using proposed technique, (b) output current and load current using conventional droop technique, (c) inverters $\mathrm{P}$ and $\mathrm{Q}$ and loads $\mathrm{P}$ and $\mathrm{Q}$ using proposed technique, and (d) inverters $\mathrm{P}$ and $\mathrm{Q}$ and loads $\mathrm{P}$ and $\mathrm{Q}$ using conventional droop technique. 


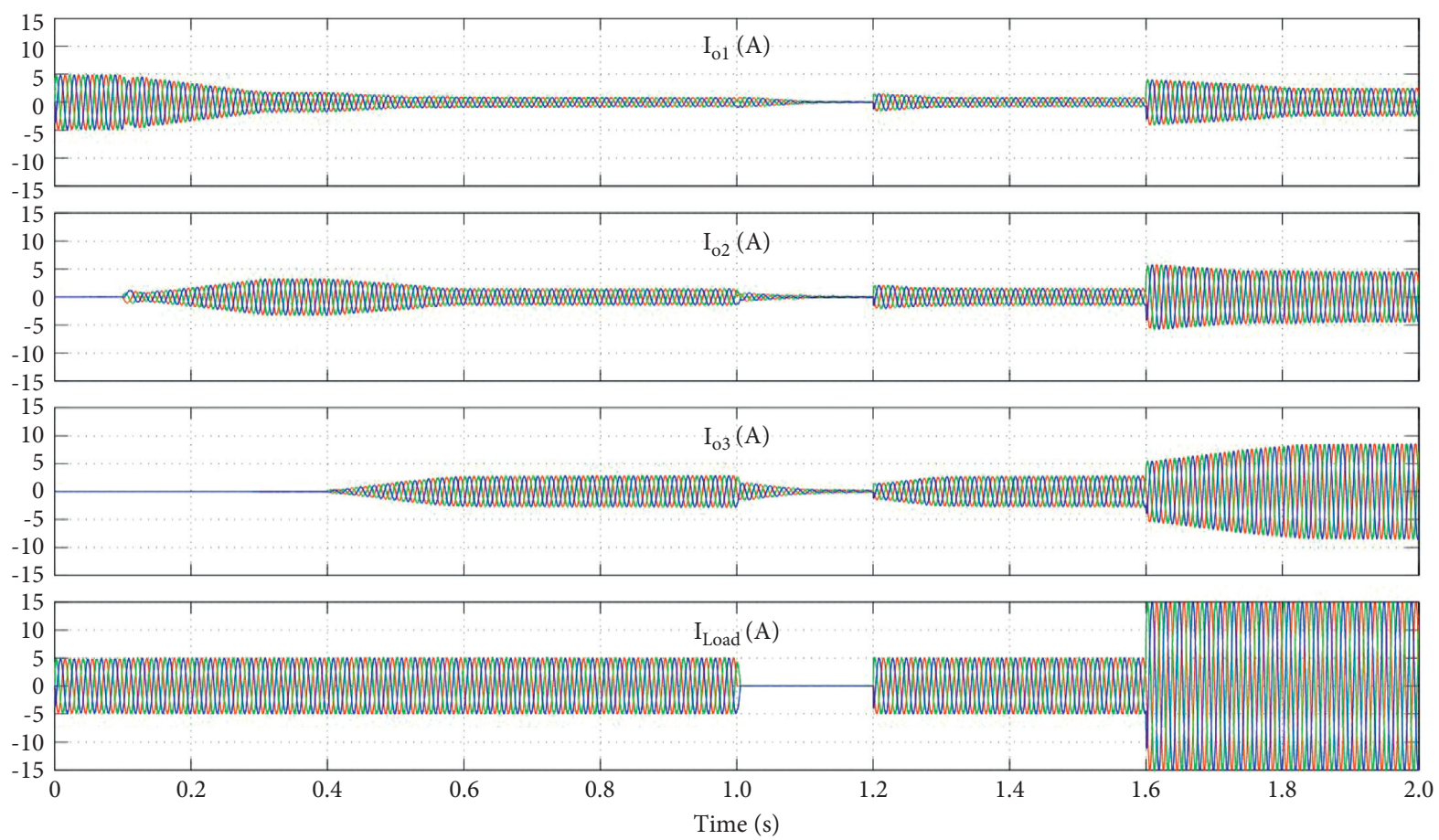

(a)
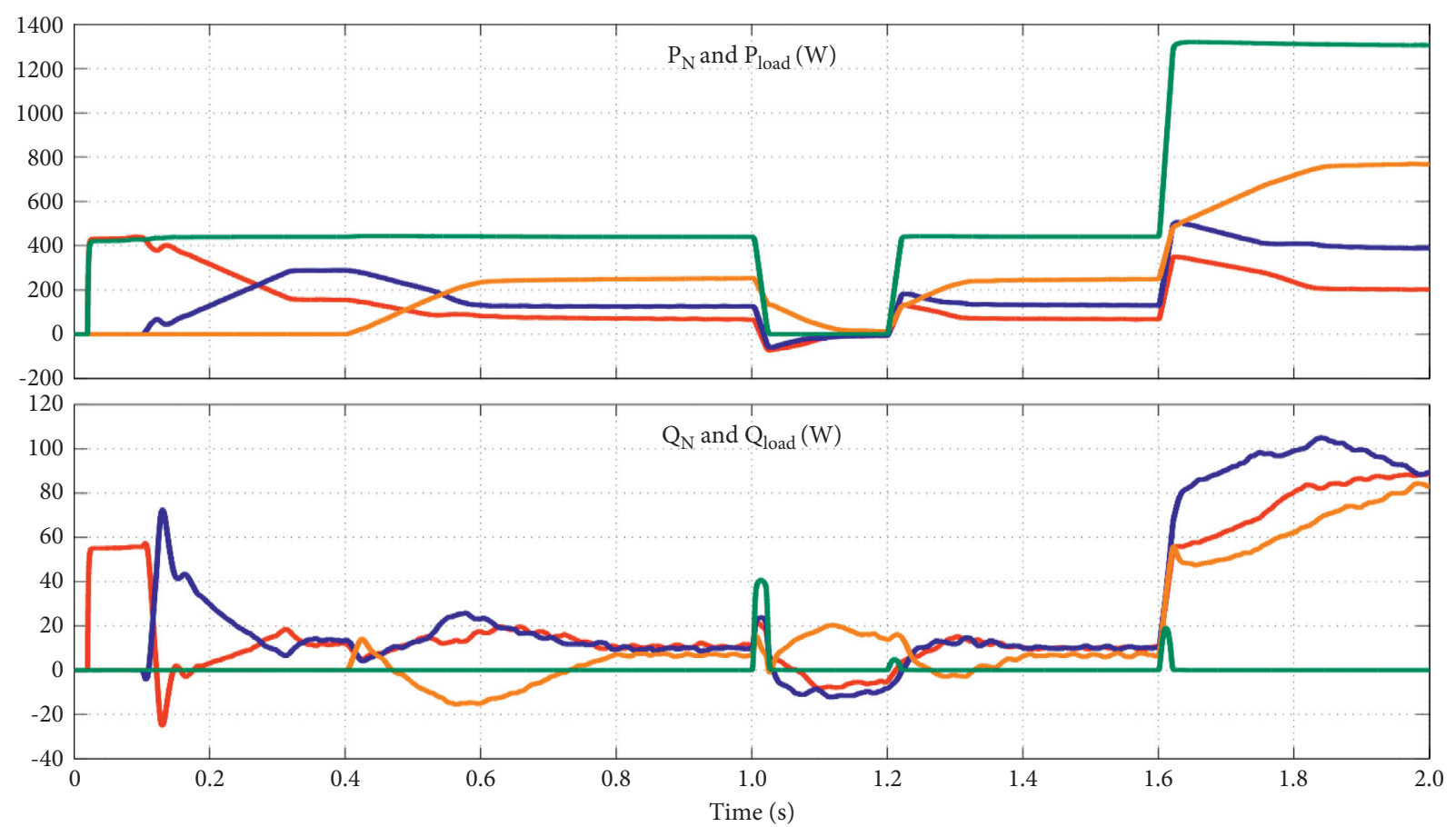

Inv1
Inv2

- Inv3

(b)

FIgURE 12: Simulation results for part II. (a) Output currents and load currents using proposed technique and (b) inverters P and Q and loads $\mathrm{P}$ and $\mathrm{Q}$ using proposed technique. 


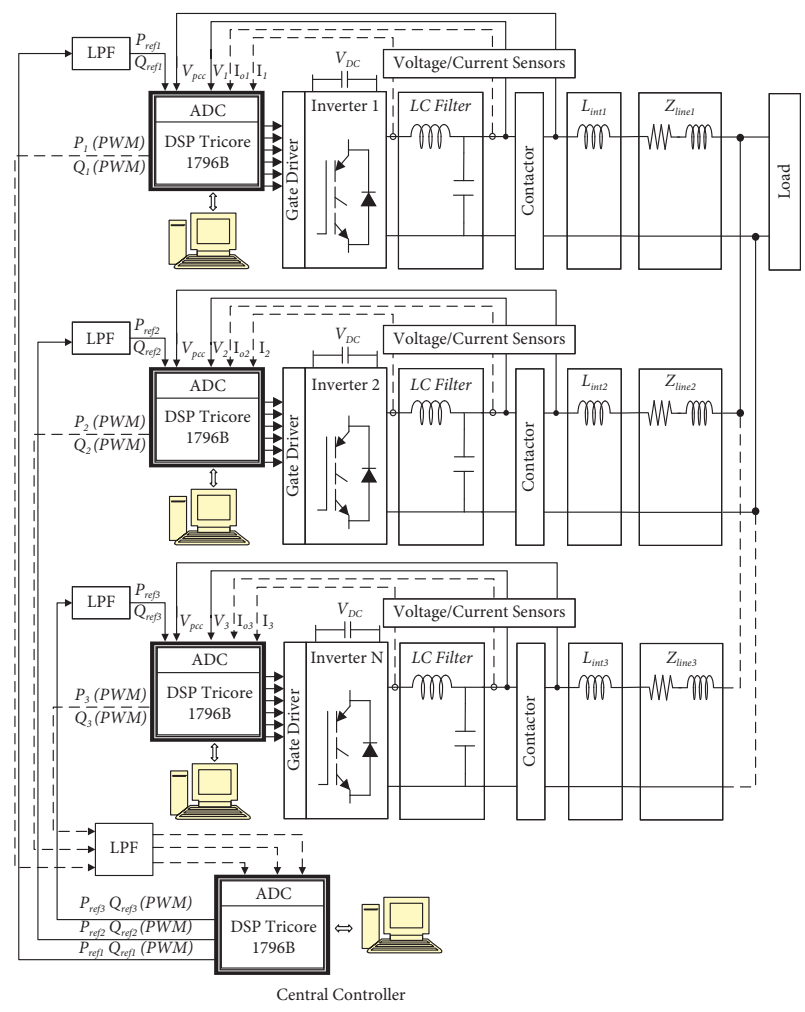

(a)

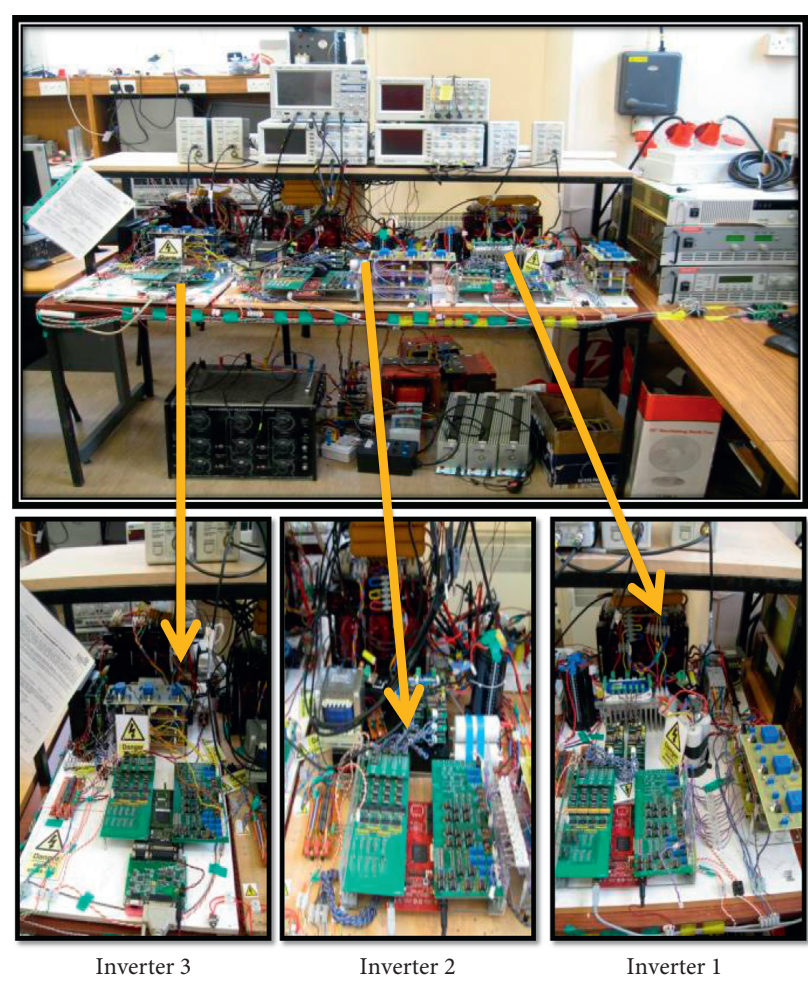

(b)

FIgURE 13: Hardware implementation. (a) Hardware arrangement. (b) Experimental test rig.

5.2. Simulation Part II. This part presents simulation results when the three inverters share active and reactive powers by ratios of $1: 2: 4$ and $1: 1: 1$, respectively, to emphasize its accuracy against different distribution of output powers. Figure 12(a) shows the output current of the three inverters and total load current waveforms. Figure 12(b) displays active and reactive power output of the three inverters and load active and reactive power. It can be seen that the proposed power sharing is able to force the inverters active and reactive output powers to follow the ratios set by the central controller, within less than 5 cycles $(100 \mathrm{~ms})$. When an additional load is introduced at $t=1.6 \mathrm{~s}$, all inverters are still able to satisfy the required power ratios set by the central controller.

\section{Results and Discussion: Experimental Analysis}

A scaled down prototype of microgrid consists of three inverters and a number of local loads are constructed to validate the practicality of the proposed power sharing scheme. Figure 13 shows hardware arrangement and picture of the experimental test rig. Each inverter is controlled by an Infineon TriCore ${ }^{\mathrm{TM}}$ TC1796B. The same DSP is used for the central controller.

The communication is implemented using PWM channels at the source and low pass filters at the destination targets as previously explained. This approach is chosen for its simplicity and considering close proximity of the inverters. The test rig parameters are the same as in the simulation section. Experiential results are organized in the same order as in simulation. An additional case that demonstrates the performance of the proposed power sharing scheme under nonlinear load is presented.

6.1. Experiment Part I. Figure 14 shows the experimental results under different operating conditions when the three parallel inverters equally shared the active power and reactive power needed by the load (by ratio of $1: 1: 1$ ). Figure 14(a) shows system transient response when inverter 2 is introduced to the load bus in the microgrid, while Figure 14(b) presents experimental waveforms that illustrate system steady state and transient response when inverter 3 is introduced. It can be observed that the power sharing between the inverters is achieved without any inrush current or significant transients, and thanks to synchronization method adopted in this paper and proposed power sharing scheme. Figure 14(c) depicts the system response during sudden disconnection of the main load. Circulating currents are observed to flow between the inverters after the load is disconnected. That is because the line impedance mismatches which is explained in [34]. Obviously, the proposed controller is able to damp these currents. Figure 14(d) shows that the circulating currents between inverters when the main load is disconnected are small (around $300 \mathrm{~mA}$ peak to peak). Waveforms that illustrate the system response during transition from light load to full load are presented in Figure 14(e). Results that illustrate the applicability of the 


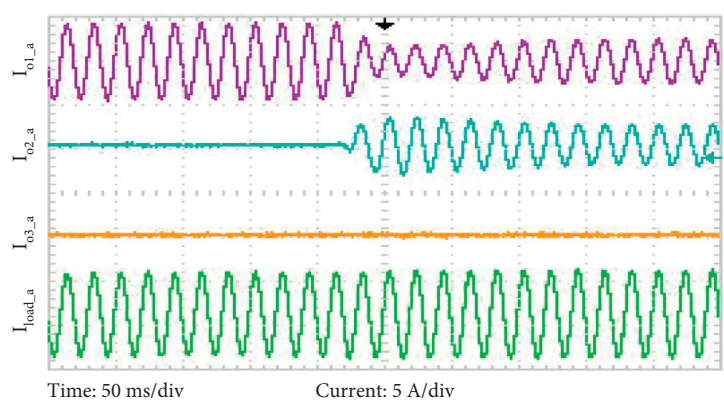

(a)

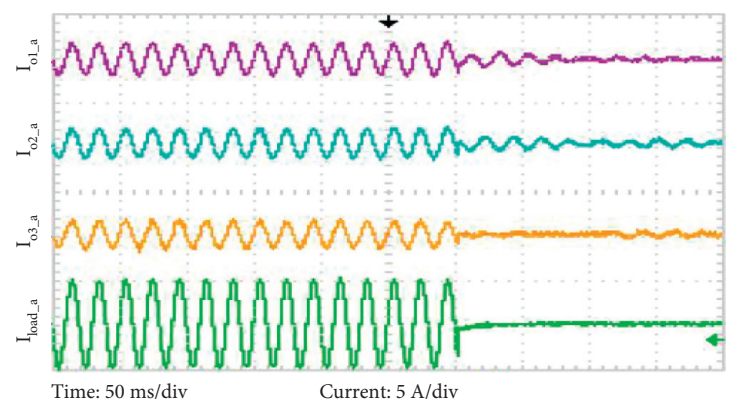

(c)

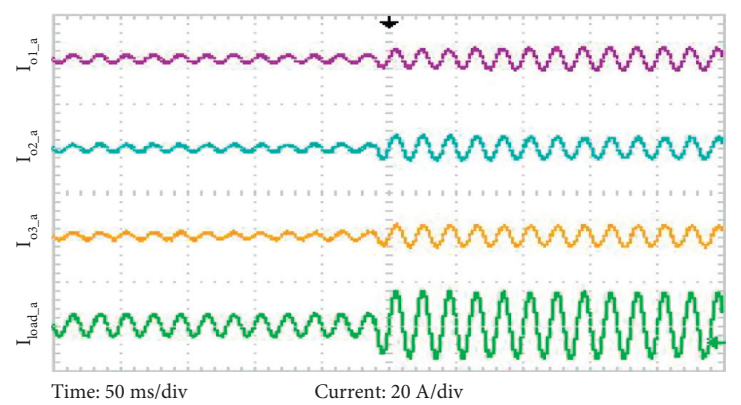

(e)

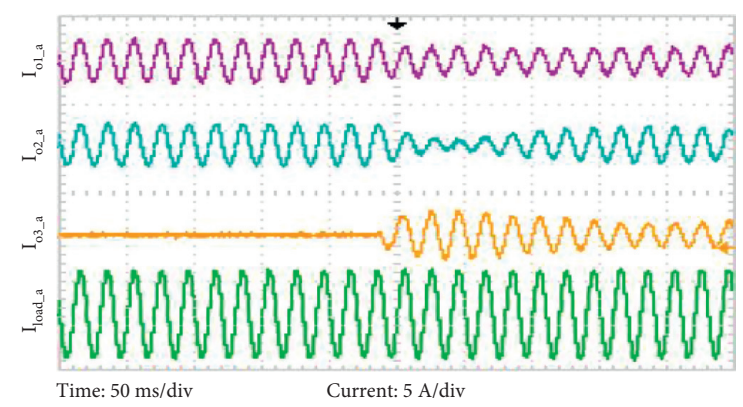

(b)

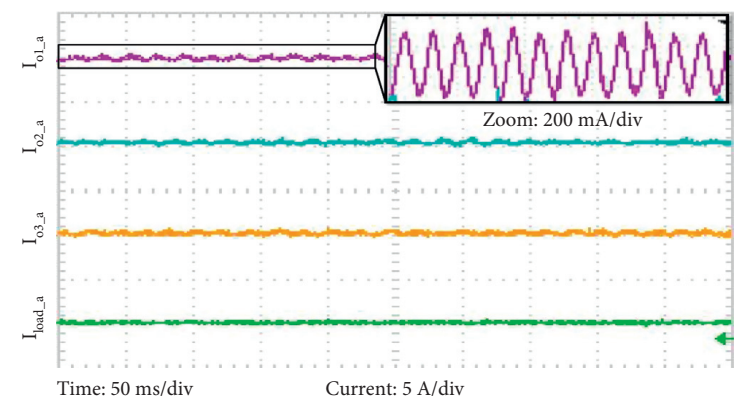

(d)

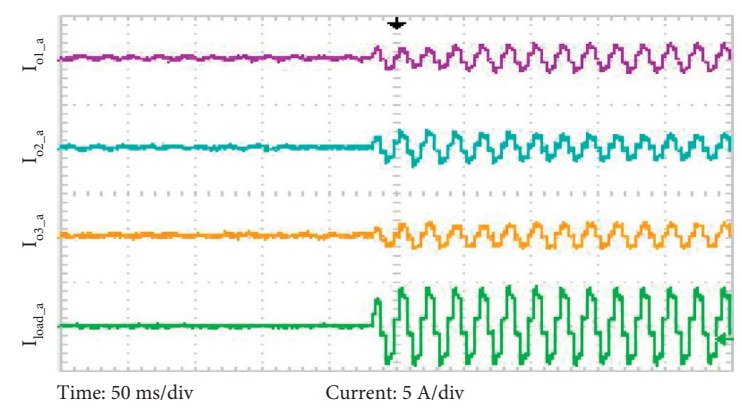

(f)

FIGURE 14: $I_{o 1}, I_{o 2}, I_{o 3}$, and $I_{\text {load }}$ waveforms under different operational conditions with the active and reactive ratios set to $1: 1: 1$. (a) Inverter 1 is supplying the load, and Inverter 2 is connected to microgrid. (b) Inverters 1 and 2 are supplying the load, and inverter 3 is connected to microgrid. (c) Transient performance from half load to no load. (d) Circulating current under no load condition. (e) Transient performance from half load to full load. (f) Transient performance from no load to rectifier type load.

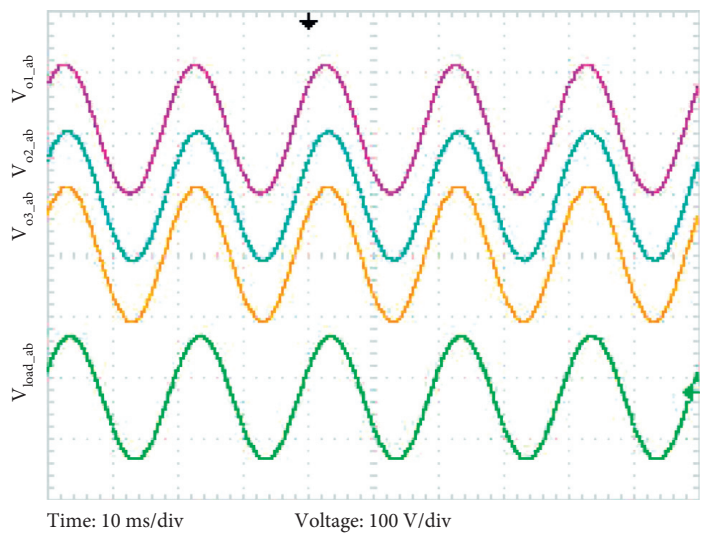

FIGURE 15: Output voltage of three inverters and load voltage when all the inverter is connected to the microgrid and supplying both load 1 and load 2. 


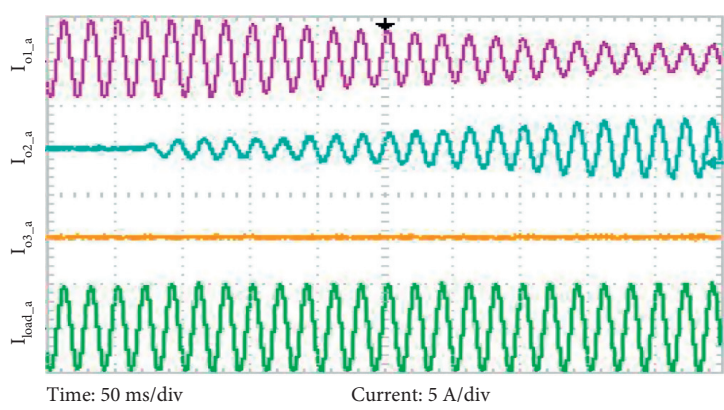

(a)

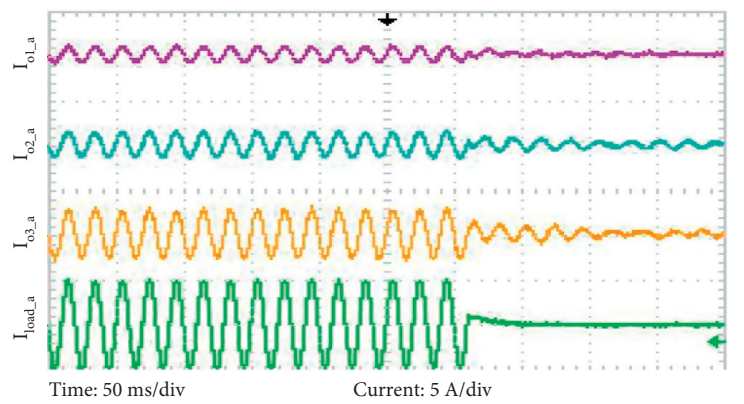

(c)

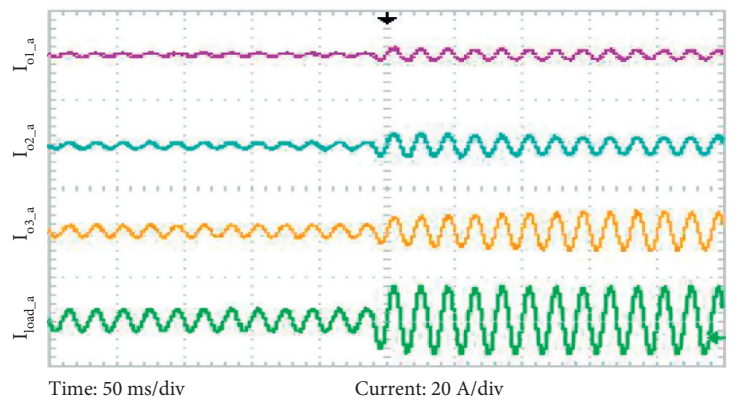

(e)

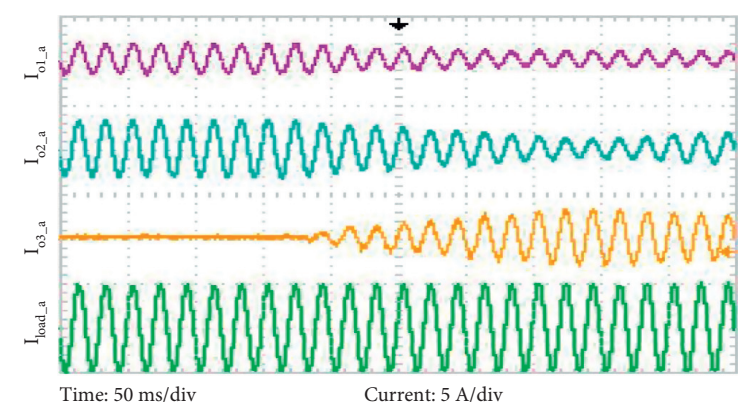

(b)

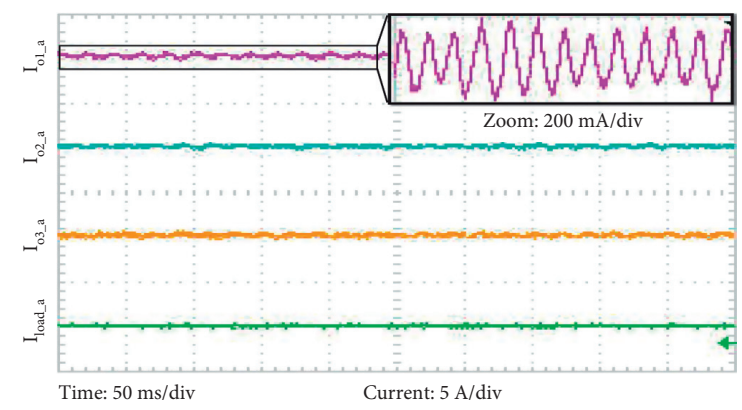

(d)

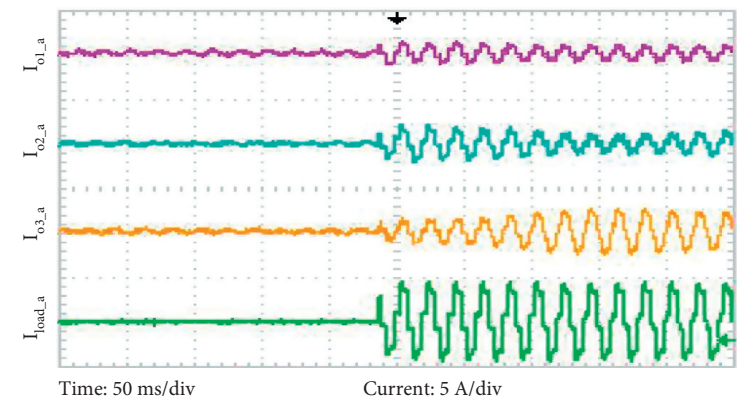

(f)

FIGURE 16: $I_{1}, I_{2}, I_{3}$, and $I_{\text {load }}$ waveforms under different operational conditions with the active power ratio is set to $1: 2: 4$ and reactive power ratio to $1: 1: 1$. (a) Inverter 1 is supplying the load, and Inverter 2 is connected to microgrid. (b) Inverter 1 and 2 are supplying the load, and Inverter 3 is connected to microgrid. (c) Transient performance from half load to no load. (d) Circulating current under no load condition. (e) Transient performance from half load to full load. (f) Transient performance from half load to rectifier type load.

proposed power sharing scheme to nonlinear load are displayed in Figure 14(f) when a rectifier feeds a passive load is introduced at the main AC bus. It is observed that the proposed power sharing is able to cope with nonlinear load that injects significant current harmonics.

The output voltage of all the three inverters and load voltage when all the inverters are connected to microgrid are shown in Figure 15.

6.2. Experiment Part II. In this part, the active power ratio and reactive power ratio are set to $1: 2: 4$ and $1: 1: 1$, respectively. This means $P_{1}=(1 / 7) P_{L}, P_{2}=(2 / 7) P_{L}$, and $P_{3}=(4 / 7) P_{L} ; \quad Q_{1}=(1 / 3) Q_{L}, \quad Q_{2}=(1 / 3) Q_{L}, \quad$ and $Q_{3}=(1 / 3) Q_{L}$, where $P_{L}$ and $Q_{L}$ are total load active and reactive powers and $P_{j}$ and $Q_{j}$ where $j=1$ to 3 present active and reactive power outputs of the inverters 1,2 , and 3 . The experimental results of three parallel-connected inverters under different operational conditions are shown in Figure 16. In Figure 16(a), the transient performance when inverter 2 is connected to microgrid is shown. This result shows smooth transient performance, and after $350 \mathrm{~ms}$, both inverters are able to achieve the specified power ratio. The same good transient performances are observed when inverter 3 is connected to the microgrid, and this is shown in Figure 16(b).

The steady state performance of the three inverters supplying load 1 and transient performance when the load is disconnected are shown in Figure 16(c). In Figure 16(d), the circulating currents among the parallel inverters are shown, and they are small in magnitude. The transient performance from partial loading to full loading is shown in Figure 16(e), 


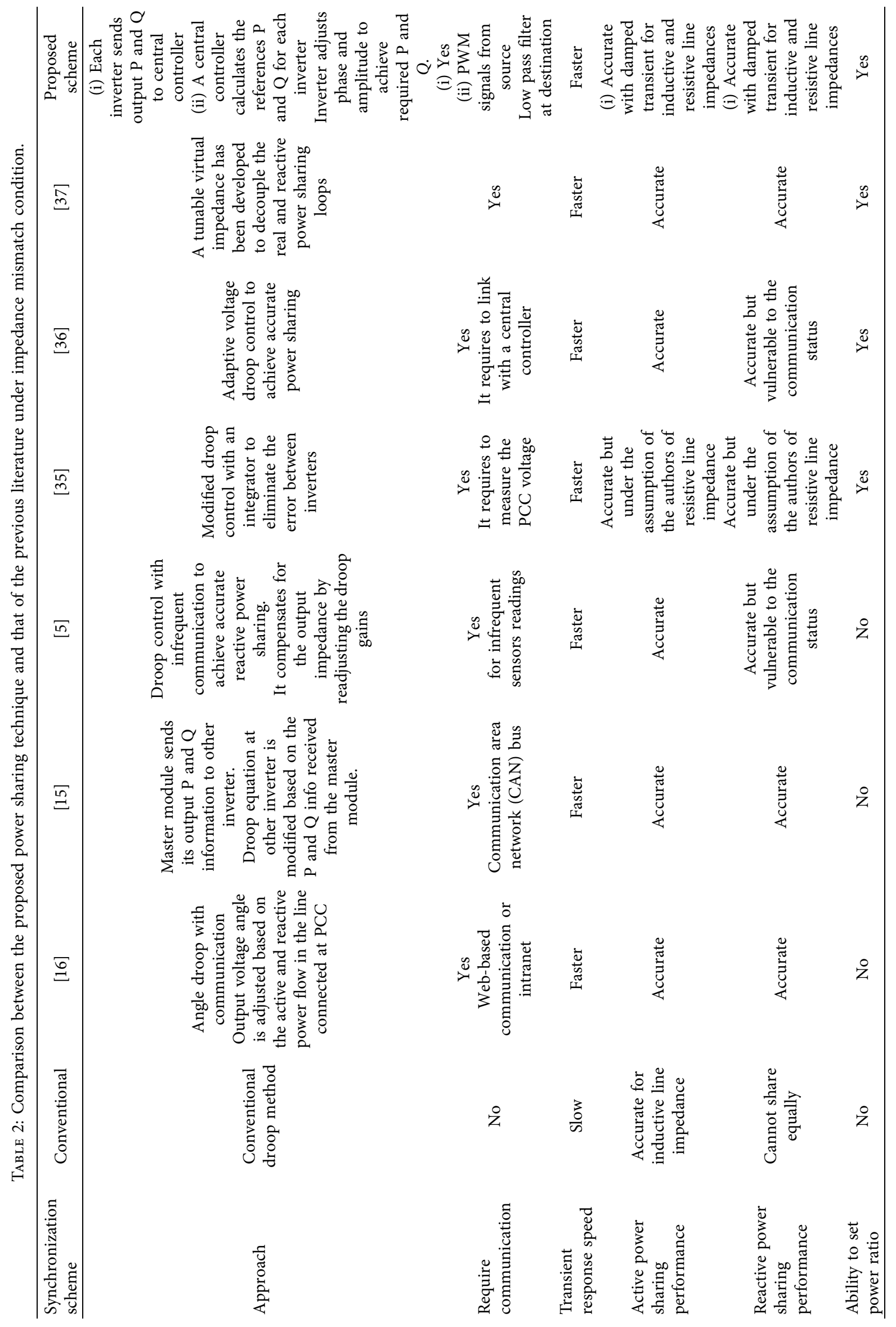


and it can be seen that the specified ratio is achieved. Finally, Figure 16(f) depicts that this controller is able to achieve the same good performance under nonlinear type load.

The simulation and experimental results clearly indicate the superiority of this technique in term of power sharing compared to the conventional droop technique. Additionally, the ability to set the required ratio gives extraflexibility on power management. Table 2 compares the proposed power sharing technique to some of the existing techniques, including droop.

\section{Conclusion}

This paper proposed a new power sharing scheme for parallel-connected inverters in islanded microgrid. This technique requires a low-bandwidth communication between inverters and central controller to exchange inverter active and reactive power output information. It has been shown that the proposed power sharing outperforms the conventional droop control as it has faster dynamic response and better sharing of reactive power between the inverters that use different line impedances and able to damp the circulating currents. Simulation and hardware implementation results have demonstrated that the proposed power sharing technique is robust under impedance mismatches, load steps, nonlinear load conditions, and demonstrated its hot swap capability. The ability to set the specific active and reactive power ratios gives flexibility to the utility owner to manage the available power in an efficient manner, which enables power demand management and reforming including peak shifting, capping, and bidirectional power flow.

\section{Data Availability}

The data used to support the findings of the study are available from the first author upon request.

\section{Conflicts of Interest}

The authors declare that they have no conflicts of interest.

\section{References}

[1] W. R. Issa, A. H. E. Khateb, M. A. Abusara, and T. K. Mallick, "Control strategy for uninterrupted microgrid mode transfer during unintentional islanding scenarios," IEEE Transactions on Industrial Electronics, vol. 65, no. 6, pp. 4831-4839, 2018.

[2] P. Sreekumar and V. Khadkikar, "Adaptive power management strategy for effective volt-ampere utilization of a photovoltaic generation unit in standalone microgrids," IEEE Transactions on Industry Applications, vol. 54, no. 2, pp. 1784-1792, 2018.

[3] W. R. Issa, M. A. Abusara, and S. M. Sharkh, "Control of transient power during unintentional islanding of microgrids," IEEE Transactions on Power Electronics, vol. 30, no. 8, pp. 4573-4584, 2015.

[4] M. Hossain, H. Pota, W. Issa, and M. Hossain, "Overview of AC microgrid controls with inverter-interfaced generations," Energies, vol. 10, no. 9, p. 1300, 2017.
[5] W. Issa, S. Sharkh, T. Mallick, and M. Abusara, "Improved reactive power sharing for parallel-operated inverters in islanded microgrids," Journal of Power Electronics, vol. 16, no. 3, pp. 1152-1162, 2016.

[6] J. M. Guerrero, L. GarciadeVicuna, J. Matas, M. Castilla, and J. Miret, "A wireless controller to enhance dynamic performance of parallel inverters in distributed generation systems," IEEE Transactions on Power Electronics, vol. 19, no. 5, pp. 1205-1213, 2004.

[7] R. Majumder, B. Chaudhuri, A. Ghosh, R. Majumder, G. Ledwich, and F. Zare, "Improvement of stability and load sharing in an autonomous microgrid using supplementary droop control loop," IEEE Transactions on Power Systems, vol. 25, no. 2, 2010.

[8] S.-J. Ahn, J.-W. Park, I.-Y. Chung, S.-I. Moon, S.-H. Kang, and S.-R. Nam, "Power-sharing method of multiple distributed generators considering control modes and configurations of a microgrid," IEEE Transactions on Power Delivery, vol. 25, no. 3, pp. 2007-2016, 2016.

[9] Y. W. Li and C. N. Kao, "An accurate power control strategy for power-electronics-interfaced distributed generation units operating in a low-voltage multibus microgrid," IEEE Transactions on Power Electronics, vol. 24, no. 12, pp. 2977-2988, 2009.

[10] E. Rokrok and M. E. H. Golshan, "Adaptive voltage droop scheme for voltage source converters in an islanded multibus microgrid," IET Generation, Transmission \& Distribution, vol. 4, pp. 562-578, 2010.

[11] Y. Mohamed and E. F. El-Saadany, "Adaptive decentralized droop controller to preserve power sharing stability of paralleled inverters in distributed generation microgrids," IEEE Transactions on Power Electronics, vol. 23, pp. 2806-2816, 2008.

[12] M. N. Marwali, J.-W. Jung, and A. Keyhani, "Control of distributed generation systems-part II: load sharing control," IEEE Transactions on Power Electronics, vol. 19, no. 6, pp. 1551-1561, 2004.

[13] I.-Y. Chung, W. Liu, D. A. Cartes, E. G. Collins, and S.-I. Moon, "Control methods of inverter-interfaced distributed generators in a microgrid system," IEEE Transactions on Industry Applications, vol. 46, no. 3, pp. 1078-1088, 2010.

[14] S. T. Cady, A. D. Dominguez-Garcia, and C. N. Hadjicostis, "A distributed generation control architecture for islanded ac microgrids," IEEE Transactions on Control Systems Technology, vol. 23, no. 5, pp. 1717-1735, 2015.

[15] Y. Zhang and H. Ma, "Theoretical and experimental investigation of networked control for parallel operation of inverters," IEEE Transactions on Industrial Electronics, vol. 59, no. 4, pp. 1961-1970, 2012.

[16] R. Majumder, G. Ledwich, A. Ghosh, S. Chakrabarti, and F. Zare, "Droop control of converter-interfaced microsources in rural distributed generation," IEEE Transactions on Power Delivery, vol. 25, pp. 2768-2778, 2010.

[17] R. Al Badwawi, W. Issa, M. Abusara, and T. Mallick, "Power management of AC islanded microgrids using fuzzy logic," in Proceedings of the 8th IET International Conference on Power Electronics, Machines and Drives (PEMD 2016), Glasgow, UK, April 2016.

[18] R. Issa, T. K. Mallick, and M. Abusara, "Supervisory control for power management of an islanded AC microgrid using a frequency signalling-based fuzzy logic controller," IEEE Transactions on Sustainable Energy, vol. 10, no. 1, pp. 94-104, 2019.

[19] T. F. Wu, Y. K. Chen, Y. H. Huang, W. Tsai-Fu, C. Yu-Kai, and $\mathrm{H}$. Yong-Heh, "3C strategy for inverters in parallel operation achieving an equal current distribution," IEEE 
Transactions on Industrial Electronics, vol. 47, no. 2, pp. 273-281, 2000.

[20] Y. Pei, G. Jiang, X. Yang, and Z. Wang, "Auto-master-slave control technique of parallel inverters in distributed AC power systems and UPS," in Proceedings of the 2004 IEEE 35th Annual Power Electronics Specialists Conference (IEEE Cat. No.04CH37551), Aachen, Germany, June 2004.

[21] A. M. Roslan, K. H. Ahmed, S. J. Finney, and B. W. Williams, "Improved instantaneous average current-sharing control scheme for parallel-connected inverter considering line impedance impact in microgrid networks," IEEE Transactions on Power Electronics, vol. 26, pp. 702-716, 2011.

[22] Y. Xing, L. Huang, S. Sun, and Y. Yan, "Novel control for redundant parallel UPSs with instantaneous current sharing," in Proceedings of the Power Conversion Conference-Osaka 2002 (Cat. No.02TH8579), Osaka, Japan, April 2002.

[23] M. A. Abusara, S. M. Sharkh, and J. M. Guerrero, "Improved droop control strategy for grid-connected inverters," Sustain. Energy, Grids Networks, vol. 1, pp. 10-19, 2015.

[24] S.-H. Hu, C.-Y. Kuo, and T.-L. Lee, "Design of virtual inductance for droop-controlled inverter with seamless transition between islanded and grid-connected operations," 2012 IEEE Energy Conversion Congress and Exposition (ECCE), vol. 2012, pp. 4383-4387, 2012.

[25] H. Jinwei He, L. Yun Wei Li, J. M. Guerrero, J. C. Vasquez, and F. Blaabjerg, "An islanding microgrid reactive power sharing scheme enhanced by programmed virtual impedances," in Proceedings of the 2012 3rd IEEE International Symposium on Power Electronics for Distributed Generation Systems (PEDG), pp. 229-235, Aalborg, Denmark, June 2012.

[26] L. G. d. V. Josep, M. Castilla, and J. Miret, "Output impedance design of parallel-connected UPS inverters with wireless loadsharing control," IEEE Transactions on Industrial Electronics, vol. 52, no. 4, 2005.

[27] X. Chen, L. Li, H. Shan, Y. Kang, and J. Chen, "Parallel operation system of high frequency modularized UPS based on distributed logic control," IEEE International Conference on Electric Machines and Drives, 2005.

[28] M. Azrik, K. H. Ahmed, S. J. Finney, and B. W. Williams, "Voltage synchronization scheme based on zero crossing detection for parallel connected inverters in AC microgrids," in Proceedings of the 2012 IEEE International Symposium on Industrial Electronics (ISIE), pp. 588-593, Hangzhou, China, May 2012.

[29] C. Zhang, J. Guerrero, J. Vasquez, and E. Coelho, "Control architecture for parallel inverter in uninterruptible power systems-part I: control design and experimental results," IEEE Transactions on Power Electronics, vol. 31, no. 7, p. 1, 2015.

[30] H. Mahmood, D. Michaelson, and J. Jiang, "Strategies for independent deployment and autonomous control of PV and battery units in islanded microgrids," IEEE Journal of Emerging and Selected Topics in Power Electronics, vol. 3, no. 3, pp. 742-755, 2015.

[31] W. Issa, F. Al-Naemi, G. Konstantopoulos, S. Sharkh, and M. Abusara, "Stability analysis and control of a microgrid against circulating power between parallel inverters," Energy Procedia, vol. 157, 2018.

[32] W. Issa, M. Abusara, S. Sharkh, and T. Mallick, "A small signal model of an inverter-based microgrid including DC link voltages," in Proceedings of the 2015 17th European Conference on Power Electronics and Applications (EPE'15 ECCE-Europe), Geneva, Switzerland, September 2015.
[33] W. Issa, A. El Khateb, N. Anani, and M. Abusara, "Smooth mode transfer in AC microgrids during unintentional islanding," Energy Procedia, vol. 134, pp. 12-20, 2017.

[34] W. Issa, S. Sharkh, and M. Abusara, "Hybrid generators-based AC microgrid performance assessment in island mode," IET Power Electronics, vol. 12, no. 8, pp. 1973-1980, 2019.

[35] Q.-C. Zhong, "Robust droop controller for accurate proportional load sharing among inverters operated in parallel," IEEE Transactions on Industrial Electronics, vol. 60, no. 4, pp. 1281-1290, 2013.

[36] H. Mahmood, D. Michaelson, J. Jiang, and S. Member, "Reactive power sharing in islanded microgrids using adaptive voltage droop control," IEEE Transactions on Smart Grid, vol. 6, no. 6, pp. 3052-3060, 2015.

[37] L. Lin, Q. Guo, Z. Bai, and H. Ma, "An enhanced power sharing strategy for islanded microgrids considering impedance matching for both real and reactive power," Journal of Power Electronics, vol. 17, no. 1, pp. 282-293, 2017. 